\title{
Timing of acid weathering on Mars: A kinetic-thermodynamic assessment
}

\author{
Mikhail Y. Zolotov ${ }^{1}$ and Mikhail V. Mironenko ${ }^{2}$ \\ Received 19 December 2006; revised 23 February 2007; accepted 24 April 2007; published 27 July 2007.
}

[1] Weathering of olivine basalt by $\mathrm{H}_{2} \mathrm{SO}_{4}-\mathrm{HCl}$ aqueous solutions at the conditions of early Mars was investigated through numerical modeling in a system open with respect to $\mathrm{CO}_{2}$ and $\mathrm{O}_{2}$ only. The model includes dissolution rates of primary and secondary minerals and oxidation rate of aqueous $\mathrm{Fe}^{2+}$, as well as chemical equilibration among solutes, dissolved gases, and precipitates. The results reveal fast dissolution of Fe-Mg minerals at low $\mathrm{pH}$, followed by preferential dissolution of plagioclase at higher $\mathrm{pH}$. Correspondingly, solutions evolve from acidic, $\mathrm{Mg}-\mathrm{Ca}-\mathrm{Fe}^{2+}-\mathrm{Fe}^{3+}-\mathrm{Al}^{3+}$ compositions toward Na-rich alkaline fluids. The period over which neutralization and mineral precipitation may occur is shorter at higher initial $\mathrm{pH}$, lower water to rock ratios, and larger mineral surface areas. Early stages of weathering are characterized by the formation of amorphous silica, goethite, and kaolinite, while zeolites and carbonates form considerably later at higher $\mathrm{pH}$, where silica dissolves. Slow oxidation of $\mathrm{Fe}^{2+}$ causes precipitation of ferrous phyllosilicates. Comparison with Martian observations indicate that amorphous silica, $\mathrm{Fe}^{3+}$ oxyhydroxides, and $\mathrm{Mg}$-, $\mathrm{Ca}-$, and $\mathrm{Fe}$-sulfates could have formed during multiple short-term episodes of acid weathering that were terminated by freezing and/or evaporation. Throughout history, impact generation of oxidants (e.g., $\mathrm{O}_{2}, \mathrm{SO}_{3}, \mathrm{NO}_{2}$ ) caused formation of strong acids and incremental $\mathrm{Fe}^{2+}$ oxidation, the processes that are not efficient during $\mathrm{O}_{2}$-deficient periods of volcanic degassing. Although impact-generated acid rainfalls could have caused intense weathering and erosion in Noachian time, dilution of acids and a prolonged existence of surface solutions favored local neutralization of solution, and formation, transport and deposition of clays.

Citation: Zolotov, M. Y., and M. V. Mironenko (2007), Timing of acid weathering on Mars: A kinetic-thermodynamic assessment, J. Geophys. Res., 112, E07006, doi:10.1029/2006JE002882.

\section{Introduction}

[2] The mineralogy and chemistry of Martian materials is consistent with aqueous weathering of primary mafic and ultramafic rocks. Sulfates, chlorides, carbonates, clay minerals, ferric oxyhydroxides, and silica phases detected in Martian soils and rocks usually form in aqueous environments [Clark et al., 1982, 2005; Bell et al., 2000; Bridges et al., 2001; Ming et al., 2006; Morris et al., 2006; Glotch et al., 2006; Ruff et al., 2006; Bibring et al., 2005, 2006]. Aqueous processes are supported by S-Mg correlations, the high and variable $\mathrm{Br} / \mathrm{Cl}$ ratio in soils, altered, and sedimentary rocks, variable $\mathrm{Fe}^{3+}, \mathrm{P}$, and $\mathrm{Al}$ contents, sulfate cements, as well as vugs and cracks filled with bright material in basalts [Rieder et al., 2004; McSween et al., 2004, 2006; Gellert et al., 2006; Clark et al., 2005; Haskin et al., 2005; Ming et al., 2006]. Because liquid water is not

\footnotetext{
${ }^{1}$ School of Earth and Space Exploration, Arizona State University, Tempe, Arizona, USA.

${ }^{2}$ Vernadsky Institute of Geochemistry and Analytical Chemistry, Russian Academy of Sciences, Moscow, Russia.
}

Copyright 2007 by the American Geophysical Union. 0148-0227/07/2006JE002882\$09.00 stable on the present surface, alteration must have occurred earlier in history, consistent with morphologic evidence of fluvial activity and intense erosion [e.g., Carr, 1996; Craddock and Howard, 2002].

[3] Observations indicate a broad range of $\mathrm{pH}$ for aqueous weathering. Alteration in neutral to alkaline conditions is consistent with the presence of carbonates and smectites in Martian meteorites [Bridges et al., 2001; Warren, 1998], and smectites in Noachian deposits [Poulet et al., 2005]. The detection of jarosite in layered rocks at Meridiani Planum provides evidence for a low-pH environment [Klingelhöfer et al., 2004; Clark et al., 2005; McLennan et al., 2005]. In Gusev crater, multiple signs of acid weathering are observed in excavated soils, surfaces of basaltic rocks, and altered rocks at Columbia Hills [Haskin et al., 2005; Ming et al., 2006; Morris et al., 2006; Hurowitz et al., 2006]. In particular, low-pH weathering in Gusev crater is supported by the high concentrations of $\mathrm{P}$ and the presence of $\mathrm{Fe}^{3+}$ sulfates in Paso Robles soil [Morris et al., 2006; Ming et al., 2006].

[4] Weathering by acid solutions includes rapid dissolution of major rock-forming minerals and basaltic glass, as inferred from field observations, experiments, and models [e.g., Murphy and Helgeson, 1989; White and Brantley, 
1995; White, 2004; Brantley, 2004], as well as experiments, models, and field observations aimed at exploring Martian processes [Banin et al., 1997; Tosca et al., 2004; FernándezRemolar et al., 2004, 2005; Golden et al., 2005; Hurowitz et al., 2005, 2006; Schiffman et al., 2006]. Among other actions, acidic $\mathrm{H}_{2} \mathrm{SO}_{4}-\mathrm{HCl}$ solutions convert igneous minerals to sulfates and chlorides, consistent with the chemistry and mineralogy of Martian materials [Clark and Van Hart, 1981; Banin et al., 1992; Bell et al., 2000; Bridges et al., 2001; Clark et al., 2005; Ming et al., 2006; Gendrin et al., 2005].

[5] Despite efforts to understand acid weathering in Martian environments [Burns and Fisher, 1990; Burns, 1993; Banin et al., 1997; Tosca et al., 2004; Golden et al., 2005; Hurowitz et al., 2005], the timing and conditions of alteration remain unknown. Here we developed a coupled kinetic-thermodynamic model to investigate interactions between acidic solutions and a Martian basalt. The model allows us to evaluate temporal changes in primary/secondary mineralogy and solution chemistry. Results are compared with Martian data and discussed in terms of origin and fate of acidic solutions in geologic history.

\section{Model Description}

[6] Irreversible chemical interaction of rock-forming minerals with an aqueous solution is modeled by coupling the kinetics of mineral dissolution with thermochemical equilibrium computations. The modeling is based on the following assumptions: (1) Formation of secondary solids occurs through dissolution of primary minerals, (2) oxidation of aqueous $\mathrm{Fe}^{2+}$ by dissolved $\mathrm{O}_{2}$ is kinetically controlled, (3) all species in solution are in chemical equilibrium with each other, and (4) precipitation of secondary minerals is controlled by mineral solubility and occurs faster than mineral dissolution, which is the limiting step in the process [Helgeson, 1968]. In other words, solution composition is controlled by dissolution rates of primary and secondary minerals, oxidation rates of $\mathrm{Fe}^{2+}$ solutes, equilibria among solutes, and equilibria between solutes and newly precipitated solids. At each time step, the mineral assemblage consists of unaltered primary minerals, previously formed secondary phases, and newly precipitated solids in equilibrium with solution.

[7] Weathering is modeled as a series of consecutive equilibrations in aqueous solution calculated at each time step. For each equilibrium computation, elemental mass balance is calculated from the chemical composition of aqueous solution at the previous step and current rates of mineral dissolution. The molar amount of a mineral $(i)$ dissolved at each time step is calculated using

$$
x_{i}=S_{i} r_{i} \Delta t
$$

where notations are presented in the outset. Minerals precipitated at previous time steps are designated as primary phases and subjected to dissolution, unless they are in equilibrium with the current solution. The duration of each time step is determined numerically from a specified molar amount of the fastest dissolving mineral. Therefore similar masses are introduced into solution during each time step.
[8] At the first time step, the surface area of primary minerals is calculated from specified grain sizes. Because only a fraction of a mineral's surface is exposed to solution, the parameter $F_{S}$ is used for each mineral to simulate fissuring of grains, rock disintegration, effective porosity, etc. For subsequent time steps, surface areas of primary minerals are computed by taking into account shrinking grain sizes. Surface areas of secondary minerals are calculated from specified grain sizes and amounts of precipitates. This is a reasonable assumption for clay and hydroxide/ oxyhydroxide phases that often possess preferred grain sizes in aqueous media. Correspondingly, the number of grains of secondary phases changes during weathering.

[9] For the same volume of mineral grains, total surface area of spherical grains is inverse proportional to their radius,

$$
S_{i}=3 V_{i} R_{i}^{-1}
$$

and combining equations (1) and (2) leads to the following expression:

$$
x_{i}=3 F s_{i} V_{i} R_{i}^{-1} r_{i} \Delta t .
$$

Although $F_{s_{i}}$ can change in unknown ways during weathering, it is assumed to be constant.

\subsection{Kinetics of Mineral Dissolution}

[10] For each time step, rates of dissolution are calculated for the current $\mathrm{pH}$ and degree of disequilibrium of solution with respect to a dissolving mineral,

$$
\begin{aligned}
r_{i}= & {\left[K_{0 H+}\left(a_{H^{+}}\right)^{b\left(T-T_{0}\right)+n_{0}}+K_{0 H 2 O}+K_{0 O H-}\left(K_{W} a_{H^{+}}^{-1}\right)^{m}\right] } \\
& \times \exp \left[\frac{E a}{R}\left(\frac{1}{T_{0}}-\frac{1}{T}\right)\right] \times\left\{1-\exp \left[p\left(\frac{\Delta G}{R T}\right)^{q}\right]\right\}
\end{aligned}
$$

In equation (4), the first term in square brackets describes the $\mathrm{pH}\left(-\log a \mathrm{H}^{+}\right)$dependence of the dissolution rate [Kump et al., 2000; Brantley, 2004]. The term $\left[b\left(T-T_{0}\right)+n_{\mathrm{o}}\right]$ defines the $\mathrm{pH}$ dependence of dissolution rate below $\mathrm{pH}$ of zero charged surface ( $\sim 5$ to $\sim 10$ [Kump et al., 2000; Brantley, 2004]) as a function of temperature. The parameter $m$ shows the $\mathrm{pH}$ dependence of rate at $\mathrm{pH}$ above that of zero charged surface. First two major terms in equation (4) designate an Arrhenius-like equation that describes the temperature dependence of the rate. The third major term is used to simulate the decrease in the rate of a dissolution reaction as chemical equilibrium is approached [Lasaga, 1981; Aagaard and Helgeson, 1982; Brantley, 2004]. The coefficients $p$ and $q$ are adjustable parameters obtained by fitting near-equilibrium kinetic data available for some minerals [Cama et al., 2000; Brantley, 2004].

[11] Our model includes 42 one-component solids that can form. Six of them are considered as primary minerals and 14 are formed as secondary phases (Table 1). Parameters of equation (4) for these minerals are depicted in Table 2. For augite, we extrapolated dissolution data from $\mathrm{pH} 1-6$ toward $\mathrm{pH} 0-8$. The validity of this extrapolation is supported by the steady dissolution rate dependence at pH 2-10 for diopside [Brantley, 2004] and a similar rate 
Table 1. Primary Minerals in Basalts and Secondary Phases Formed in Models for Acid Weathering ${ }^{\mathrm{a}}$

\begin{tabular}{|c|c|c|}
\hline Mineral & Formula & Data Source $^{\mathrm{b}}$ \\
\hline Olivine $\left(\mathrm{Fo}_{73}\right)$ & $\mathrm{Mg}_{1.46} \mathrm{Fe}_{0.54} \mathrm{SiO}_{4}$ & \\
\hline Bytownite & $\mathrm{Na}_{0.45} \mathrm{Ca}_{0.55} \mathrm{Al}_{1.55} \mathrm{Si}_{2.45} \mathrm{O}_{8}$ & \\
\hline Pigeonite & $\mathrm{Ca}_{0.188} \mathrm{Mg}_{1.21} \mathrm{Fe}_{0.557} \mathrm{Al}_{0.03} \mathrm{Si}_{2} \mathrm{O}_{6}$ & \\
\hline Augite & $\mathrm{Ca}_{0.446} \mathrm{Mg}_{1.01} \mathrm{Fe}_{0.445} \mathrm{Al}_{0.066} \mathrm{Si}_{2} \mathrm{O}_{6}$ & \\
\hline Orthopyroxene & $\mathrm{Ca}_{0.125} \mathrm{Mg}_{1.35} \mathrm{Fe}_{0.48} \mathrm{Al}_{0.03} \mathrm{Si}_{2} \mathrm{O}_{6}$ & \\
\hline Magnetite & $\mathrm{Fe}_{3} \mathrm{O}_{4}$ & \\
\hline Amorphous silica & $\mathrm{SiO}_{2}$ & 1 \\
\hline Goethite & $\alpha$-FeOOH & 4 \\
\hline Kaolinite & $\mathrm{Al}_{2} \mathrm{Si}_{2} \mathrm{O}_{5}(\mathrm{OH})_{4}$ & 1 \\
\hline $\mathrm{Fe}^{2+}$-saponite & $\mathrm{Fe}_{3.175} \mathrm{Al}_{0.35} \mathrm{Si}_{3.56} \mathrm{O}_{10}(\mathrm{OH})_{2}$ & 7 \\
\hline Daphnite & $\mathrm{Fe}_{5} \mathrm{Al}\left(\mathrm{AlSi}_{3}\right) \mathrm{O}_{10}(\mathrm{OH})_{8}$ & 3 \\
\hline Stellerite & $\mathrm{Ca}_{2} \mathrm{Al}_{4} \mathrm{Si}_{14} \mathrm{O}_{36} \cdot 14 \mathrm{H}_{2} \mathrm{O}$ & 6 \\
\hline Stilbite & $\mathrm{Ca}_{2} \mathrm{NaAl}_{5} \mathrm{Si}_{13} \mathrm{O}_{36} \cdot 16 \mathrm{H}_{2} \mathrm{O}$ & 6 \\
\hline Mg-saponite & $\mathrm{Mg}_{19} \mathrm{Al}_{2} \mathrm{Si}_{22} \mathrm{O}_{60}(\mathrm{OH})_{12}$ & 5 \\
\hline Na-saponite & $\mathrm{Na}_{2} \mathrm{Mg}_{18} \mathrm{Al}_{2} \mathrm{Si}_{22} \mathrm{O}_{60}(\mathrm{OH})_{12}$ & 5 \\
\hline Na-montmorillonite & $\mathrm{Na}_{0.35} \mathrm{Mg}_{0.35} \mathrm{Al}_{1.65} \mathrm{Si}_{4} \mathrm{O}_{10}(\mathrm{OH})_{2}$ & 7 \\
\hline Dolomite & $\mathrm{CaMg}\left(\mathrm{CO}_{3}\right)_{2}$ & 1,2 \\
\hline Calcite & $\mathrm{CaCO}_{3}$ & 1,2 \\
\hline Siderite & $\mathrm{FeCO}_{3}$ & 1 \\
\hline Gypsum & $\mathrm{CaSO}_{4} \cdot 2 \mathrm{H}_{2} \mathrm{O}$ & 4 \\
\hline
\end{tabular}

${ }^{\mathrm{a}}$ Martian basalt EETA 79001, lithology A [McSween and Jarosewich, 1983 ] is used as a proxy for composition of rock silicates. Other minerals in the models are $\mathrm{Ca}-, \mathrm{Na}-, \mathrm{Fe}-$ beidellites, $\mathrm{Ca}$-, $\mathrm{Fe}$-montmorillonites, $\mathrm{Ca}-\mathrm{Na}-$ saponites, clinochlore, greenalite, laumontite, gibbsite, boehmite, ferrihydrite, hematite, magnesite, and $\mathrm{K}-, \mathrm{Na}-, \mathrm{H}_{3} \mathrm{O}$-jarosites. Thermodynamic data for clays minerals are from Vieillard et al. [2004], Wilson et al. [2006], and Wolery and Jove-Colon [2004].

${ }^{\mathrm{b}}$ Thermodynamic data for minerals are from: 1, Helgeson et al. [1978]; 2, Plummer and Busenberg [1982]; 3, Holland and Powell [1998]; 4, Robie and Hemingway [1995]; 5, Wolery and Jove-Colon [2004]; 6, Fridriksson et al. [2001]; 7, Wilson et al. [2006]. For primary minerals, thermodynamic data are relatively unimportant because fates of these minerals are determined by dissolution kinetics.

pattern below pH 5.9-8.5 that corresponds to zero charged surfaces for single chain silicates [Kump et al., 2000]. Kinetic parameters of augite are used for all $\mathrm{Fe}^{2+}$-bearing pyroxenes. Data for montmorillonite are applied to dissolution rates of saponites and beidellites. For zeolites, we used dissolution parameters for anorthite. In the model, the inter- action of goethite with solution is controlled by its low and declining solubility at rising $\mathrm{pH}$, thus an arbitrary dissolution rate is chosen to maintain such behavior. Since the effect of temperature on $\mathrm{pH}$ dependence is not well known [Kump et al., 2000; Brantley, 2004], parameter $b$ is set to 0 .

\subsection{Oxidation Kinetics of Aqueous $\mathrm{Fe}^{2+}$}

[12] In the presence of dissolved $\mathrm{O}_{2}$, dissolution of ferrous minerals should be followed by oxidation of aqueous $\mathrm{Fe}^{2+}$, which may be accompanied by precipitation of matastable and semicrystalline ferrihydrite, $\sim \mathrm{Fe}(\mathrm{OH})_{3}$, that dehydrates to goethite, $\alpha$-FeOOH. Reactions (5)-(7) can represent the oxidation

$$
\begin{gathered}
\mathrm{Fe}^{2+}+0.25 \mathrm{O}_{2}+\mathrm{H}^{+} \longrightarrow \mathrm{Fe}^{3+}+0.5 \mathrm{H}_{2} \mathrm{O} \\
\mathrm{Fe}^{2+}+0.25 \mathrm{O}_{2}+0.5 \mathrm{H}_{2} \mathrm{O} \longrightarrow \mathrm{FeOH}^{2+}, \\
\mathrm{Fe}^{2+}+0.25 \mathrm{O}_{2}+2.5 \mathrm{H}_{2} \mathrm{O} \longrightarrow \mathrm{Fe}(\mathrm{OH})_{3}+2 \mathrm{H}^{+},
\end{gathered}
$$

at $\mathrm{pH}<2.2, \mathrm{pH}=2.2-3.5$, and $\mathrm{pH}>3.5$, respectively [cf. Singer and Stumm, 1970; Millero et al., 1987; Langmuir, 1997]. We used equation (8) to characterize the oxidation rate below $\mathrm{pH} 8$,

$$
-d\left[\mathrm{Fe}^{2+}\right] / d t=k_{1}\left[\mathrm{Fe}^{2+}\right] \times\left[\mathrm{O}_{2}\right]+k_{2}\left[\mathrm{Fe}^{2+}\right] \times\left[\mathrm{O}_{2}\right] \times\left[\mathrm{OH}^{-}\right]^{2},
$$

where values in brackets stand for concentrations of solutes [cf., Singer and Stumm, 1970], and $k_{1}$ and $k_{2}$ are rate constants representing oxidation at $\mathrm{pH}$ below and above $\sim 3.5$, respectively. Equation (8) assumes pseudo-first-order behavior with respect to dissolved $\mathrm{Fe}^{2+}$. Temperature and ionic strength dependencies of $k_{2}$ were taken from Millero et al. [1987]. We assumed that $k_{1}$ has the same dependencies as $k_{2}$.

Table 2. Parameters of Equation (4) for Calculation Rates of Mineral Dissolution

\begin{tabular}{lccccc}
\hline \multicolumn{1}{c}{ Mineral } & $E a, \mathrm{~kJ} \mathrm{~mol}^{-1}$ & $\log \left(K_{0 H^{+}}\right), \mathrm{mol} \mathrm{m}^{-2} \mathrm{~s}^{-1}$ & $n_{0}$ & $\log \left(K_{0 H 2 O}\right), \mathrm{mol} \mathrm{m}^{-2} \mathrm{~s}^{-1}$ & $\log \left(K_{0 O H-}\right), \mathrm{mol} \mathrm{m}^{-2} \mathrm{~s}^{-1}$ \\
\hline Amorphous silica $^{\mathrm{a}}$ & 62.8 & 0 & 0 & -11.0 & -9.0 \\
Anorthite $^{\mathrm{b}}$ & 79.5 & -5.9 & 1.0 & 0 & -9.4 \\
Augite $^{\mathrm{c}}$ & 87.9 & -6.7 & 0.85 & 0 & 0.3 \\
Bytownite $^{\mathrm{d}}$ & 14 & -8.6 & 0.39 & -11.6 & 0 \\
Chlorite $^{\mathrm{e}}$ & 58.6 & -9.89 & 0.49 & -13.0 & -10.2 \\
Olivine $^{\left(\mathrm{Fo}_{73}\right)^{\mathrm{f}}}$ & 92.0 & -6.73 & 0.54 & -14.3 & -10.8 \\
Kaolinite $^{\mathrm{g}}$ & 57.3 & -12.4 & 0.35 & 0 & 0 \\
Magnetite $^{\mathrm{h}}$ & 29.3 & -8.77 & 0.25 & 0 & 0.3 \\
Motmorillonite $^{\mathrm{i}}$ & 38.9 & -10.6 & 0.74 & 0 & 0 \\
\hline
\end{tabular}

${ }^{\mathrm{a}} E_{a}$ is from Rimstidt and Barnes [1980]; $\log \left(K_{\mathrm{OOH}-}\right)$ and $\log \left(K_{0 \mathrm{H} 2 \mathrm{O}}\right)$ are taken about one log unit higher than for quartz after Icenhower and Dove [2000]; $n_{0}$ is as for quartz. The coefficients for quartz are calculated from Brady and Walther [1990].

${ }^{\mathrm{b}}$ Data are from Brantley [2004] and Brady and Walther [1989].

${ }^{\mathrm{c}}$ Data are from Brantley [2004] for $\mathrm{pH}<6$.

${ }^{\mathrm{d}} E_{a}$ is from Blum and Stillings [1995]. Other parameters are estimated from Brady and Walther [1989].

${ }^{\mathrm{e}} E_{a}$ is taken as an average for silicates. Other parameters were obtained by Alekseev [2007] through approximation data from Kodama and Schnitzer [1973], Hamer et al. [2003], and Lowson et al. [2005]. Data are applied to daphnite and clinochlore.

${ }^{\mathrm{f}} E_{a}$ is from Wogelius and Walther [1992] for forsterite; $\log \left(\mathrm{K}_{0 K \mathrm{H}^{+}}\right)$and $n_{0}$ is interpolated on the basis of data for forsterite [Chen and Brantley, 2000] and fayalite [Wogelius and Walther, 1992]; $\log \left(\mathrm{K}_{0 K \mathrm{H}} \mathrm{O}\right)$ is evaluated on the basis of work by Pokrovsky and Schott [2000].

${ }^{\mathrm{g}}$ Approximated data from Cama et al. [2002], Huertas et al. [1999], Carrol and Walther [1990], Ganor et al. [1995], and Nagy et al. [1991] by Alekseev [2007].

${ }^{\mathrm{h}} E_{a}$ is from Sidhu et al. [1981]; $\log \left(K_{0 \mathrm{H}^{+}}\right)$and $n_{0}$ was obtained by Alekseev [2005] from the data of White et al. [1994] for the incongruent dissolution of magnetite (equation (11)).

${ }^{\mathrm{i}}$ Approximated data from Amram and Ganor [2005], Bauer and Berger [1998], Cama et al. [2000], and Huertas et al. [2001] by Alekseev [2007]. 
[13] We considered the kinetics of $\mathrm{Fe}^{2+}$ oxidation as consecutive dissolution and oxidation reactions, i.e., $\mathrm{Fe}^{2+}$ (in minerals) $\rightarrow \mathrm{Fe}^{2+}$ (aqueous) $\rightarrow \mathrm{Fe}^{3+}$ (aqueous). The bulk oxidation rate can be expressed as

$$
-d\left[F e^{2+}\right] / d t=k_{3}-k_{4}\left[F e^{2+}\right],
$$

where $k_{3}=\sum_{i} r_{i} S_{i} \nu_{i}$ is the bulk rate constant of zero-order dissolution reactions for ferrous minerals containing $\nu_{i}$ atoms of $\mathrm{Fe}^{2+}$ per formula unit. The rate constant, $k_{4}$, for oxidation of aqueous $\mathrm{Fe}^{2+}$ species at current $\mathrm{pH}$, a fixed concentration of dissolved $\mathrm{O}_{2}$, temperature, and ionic strength is evaluated with equation (8) and data from Singer and Stumm [1970] and Millero et al. [1987]; $k_{4}=\left[\mathrm{O}_{2}\right] \times\left(k_{1}+k_{2}\left[\mathrm{OH}^{-}\right]^{2}\right)$. Integrating equation (9) gives the expression for the molar amount of $\mathrm{Fe}^{2+}$ oxidized at each time step

$$
\Delta\left[F e^{2+}\right]=\left(\frac{k_{3}}{k_{4}}-\left[F e^{2+}\right]_{0}\right) \times\left[1-\exp \left(-k_{4} \Delta t\right)\right]
$$

where $\left[\mathrm{Fe}^{2+}\right]_{0}$ is the initial concentration of $\mathrm{Fe}^{2+}$-bearing species taken from the preceding time step. We used equation (10) to calculate the amount of oxygen added to the solution at each time step to participate in oxidation. Then, the model calculates chemical equilibrium in solution, producing new concentrations of $\mathrm{Fe}^{2+}$ and $\mathrm{Fe}^{3+}$ aqueous species and amounts of precipitated ferric minerals. Although the system is declared as open with respect to $\mathrm{O}_{2}$, specified atmospheric $P_{\mathrm{O}_{2}}$ values were only used to calculate the oxidation rate constant $k_{4}$ in equation (9). Note that in our model dissolution of magnetite also contributes ferric ions to solution and affects mass of goethite formed.

\subsection{Thermodynamic Calculations, Input Data, and Model Limitations}

[14] The thermodynamic block of the model is based on the GEOCHEQ code [Mironenko et al., 2000], which uses the Gibbs free energy minimization method to calculate chemical equilibrium in solution-gas-solid systems. Thermodynamic properties of solutes are mainly from Shock et al. [1989, 1997], and data for minerals are mainly from Helgeson et al. [1978] and Holland and Powell [1998]. Thermodynamic data for clay minerals are specified in Table 1. Note that thermodynamic data for nontronite from Wolery and Jove-Colon [2004] may not be correct [Bethke, 1996].

[15] Calculations were performed for $0^{\circ} \mathrm{C}$ in the system $\mathrm{H}-\mathrm{O}-\mathrm{S}-\mathrm{Cl}-\mathrm{C}-\mathrm{Mg}-\mathrm{Ca}-\mathrm{Al}-\mathrm{Si}-\mathrm{Na}-\mathrm{Fe}$, which was open with respect to $\mathrm{CO}_{2}$ and $\mathrm{O}_{2}$. The Martian achondrite EETA 79001 (lithology A) studied by McSween and Jarosewich [1983] was used as a proxy for mineralogical composition of Martian olivine basalt (see Table 1). The modeled rock consists of six minerals in mol/ $\mathrm{kg}$ rock: olivine $\left(\mathrm{Fo}_{73}\right), 2.69$; bytownite $\left(\mathrm{An}_{55}\right), 2.55$; pigeonite, 0.37 ; augite, 0.37 , orthopyroxene, 0.33; and magnetite, 0.07. In contrast to EETA 79001 mineralogy, all opaque minerals are represented by magnetite. For case study modeling, grain size was taken as $0.2 \mathrm{~mm}$ for silicates and $0.05 \mathrm{~mm}$ for magnetite. For primary minerals, the fractions of the exposed surface area $(F s)$ were taken as 0.01 . Secondary minerals had grain sizes of $1 \mu \mathrm{m}$ and were entirely exposed to solution. This is a good proxy for clay minerals, at least [Meunier, 2005].

[16] The case study modeling was performed for initial aqueous solutions that contained 0.05 moles $\mathrm{H}_{2} \mathrm{SO}_{4}$ and 0.0096 moles $\mathrm{HCl}$ per $\mathrm{kg}$ of water, yielding $\mathrm{pH}$ of 1.2. These and other solutions correspond to a $\mathrm{S} / \mathrm{Cl}$ molar ratio of 5.2, consistent with the composition of Martian soils at landing sites of Vikings 1 and 2, Mars Pathfinder, and the Spirit rover [Clark et al., 1982; Foley et al., 2003; Gellert et al., 2006].

[17] To simulate a termination of weathering by consumption of liquid water, we modeled freezing and evaporation for the specific times of solution evolution. The calculations were performed for the $\mathrm{H}_{2} \mathrm{O}-\mathrm{SO}_{4}-\mathrm{Cl}-\mathrm{CO}_{3}-\mathrm{Na}-$ Ca-Mg-Fe system with the FREZCHEM model [e.g., Marion, 2002; Marion et al., 2003], which uses Pitzer approach to calculate water activity and activity coefficients of solutes in concentrated solutions. Note that ferric species do not present in the FREZCHEM model because of lack of experimental data.

[18] Conceptual limitations of the coupled thermodynamickinetic model are related to neglecting (1) mass exchange with the surrounding environment (except $\mathrm{O}_{2}$ and $\mathrm{CO}_{2}$ ), (2) supersaturation of secondary phases and kinetics of precipitation, (3) differences in grain shape and $F s$ among minerals, (4) changes in grain shapes and $F s$ during weathering, (5) possible formation of metastable and amorphous phases (except silica), and (6) coatings by secondary minerals. The reliability of results is affected by high uncertainties or absence of (1) thermodynamic data for many clay minerals, zeolites, and some salts, (2) grain sizes, shapes and $F s$ for secondary minerals, and (3) questionable dissolution rates for augite (at $\mathrm{pH}>6$ ), orthopyroxene, pigeonite, and zeolites. In addition, results are affected by the accuracy of models that relate reactions rates, $\mathrm{pH}, T$, and $P_{\mathrm{O}_{2}}$. Finally, discrepancies between laboratory and natural rates of weathering [White and Brantley, 2003; White, 2004] question the application of models to complex environments. It follows that presented results should be considered as a step toward investigating the physical chemistry of low-temperature water-rock interactions rather than explicitly solving problems of acid weathering.

\section{Results}

[19] This section first describes a simulation of weathering of olivine basalt for nominal parameters of the model. We then examine the sensitivity of the model with respect to water/rock $(W / R)$ ratio, initial $\mathrm{pH}$, and atmospheric $P_{\mathrm{O}_{2}}$. Finally, we model termination of the process through freezing and evaporation of solution at specific stages of weathering.

\subsection{A Case Study of Acid Weathering}

[20] The modeling was performed for a water/rock mass ratio of unity, original solution $\mathrm{pH}$ of $1.2, F_{S}$ of 0.01 , and partial pressures of $\mathrm{O}_{2}(7.6 \mu$ bar $)$ and $\mathrm{CO}_{2}(5.3 \mathrm{mbar})$ in the present Martian atmosphere. This case may represent weathering of slightly disintegrated basalt. Results demon- 

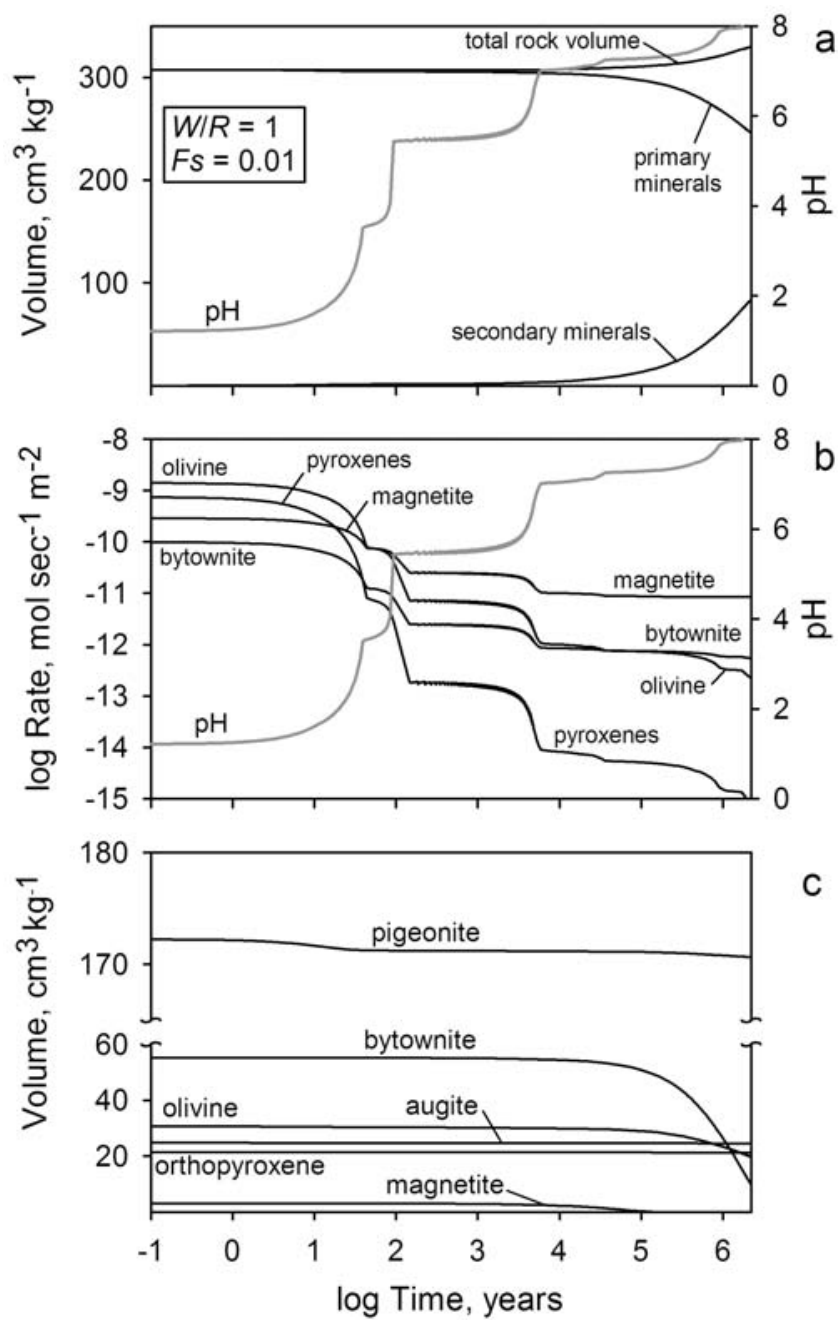

Figure 1. Temporal changes in $\mathrm{pH}$, volumes of primary and secondary minerals, and dissolution rates during acid weathering of olivine basalt. The weathering parameters are: $0^{\circ} \mathrm{C}, 1 \mathrm{bar}$, the original $\mathrm{pH}$ of $\mathrm{H}_{2} \mathrm{SO}_{4}-\mathrm{HCl}$ solution is $1.2, W / R=1, P_{\mathrm{O}_{2}}=7.3 \mu$ bar, $P_{\mathrm{CO}_{2}}=5.34$ mbar, grain sizes of silicates are $0.2 \mathrm{~mm}$; magnetite, $0.05 \mathrm{~mm}$, and $F s=0.01$. In Figure 1c, volumes of minerals are for $1 \mathrm{~kg}$ of rock. See color version of this figure in the HTML.

strate partial dissolution of primary minerals, rising $\mathrm{pH}$ to 8 , and precipitation and dissolution of secondary minerals in time. The volume of primary minerals decreased by $20 \%$, the volume of secondary phases composed $24 \%$ of the altered rock, and the total volume (without pores) rose by $7 \%$ owing to lower densities of secondary phases (Figure 1a).

[21] When the initial $\mathrm{pH}$ is low, primary minerals dissolve fastest (Figure 1b). Rapid dissolution of primary minerals causes partial neutralization of solution, so dissolution rates fall as $\mathrm{pH}$ increases. Within the studied $\mathrm{pH}$ range, each abrupt increase in $\mathrm{pH}$ decreases dissolution rates. As long as the solution remains acidic (at $0^{\circ} \mathrm{C}$, neutral $\mathrm{pH}$ is 7.48 when $\left.a \mathrm{H}^{+}=a \mathrm{OH}^{-}, K_{w}=-14.96\right)$, dissolution of olivine strongly affects the composition of solution and neutralization. Weathering of $\mathrm{Fe}^{2+}$-bearing pyroxenes is very intense only at $\mathrm{pH}<\sim 3$. As $\mathrm{pH}$ increases, a rapid decrease in dissolution rates of pyroxenes diminishes their alteration. Below $\mathrm{pH} \sim 3$, bytownite (i.e., feldspar) dissolves slower than olivine and pyroxene. Although it dissolves as fast as olivine at $\mathrm{pH} 6-$ 8 , the effect of bytownite on solution composition is larger owe to its greater abundance.

[22] Rapid dissolution of pyroxenes at low $\mathrm{pH}$ has a major effect because of their large abundance (Figure 1c). At $\mathrm{pH} 3-5$, olivine, bytownite and magnetite, which completely dissolve at some point, are most affected by dissolution. During further weathering, dissolution of bytownite is the major cause for decreasing volume of primary minerals.

[23] Amorphous silica precipitates first and remains the most abundant secondary phase until $\mathrm{pH} \sim 6$ (Figures $2 \mathrm{a}$ and $2 b$ ). Goethite forms second and at first stages its formation is mostly attributed to dissolution of magnetite. Formation of clay minerals (kaolinite, $\mathrm{Fe}^{2+}$-saponite), consumes excess silica from solution, including $\mathrm{SiO}_{2}$ supplied from dissolution of previously precipitated silica. Abundant zeolites occur after a long period of time when the solution becomes alkaline. Stellerite (Ca-zeolite) forms first but is replaced by stilbite (Ca-Na-zeolite). Dolomite and $\mathrm{Mg}$-saponite reach saturation at about neutral conditions. Subsequent weathering in alkaline solutions is characterized by increasing amounts of zeolites, clay minerals, and dolomite. Dissolution of plagioclase supplies $\mathrm{Na}$, which is incorporated in clays (Na-saponite and Na-montmorillonite) and stilbite. This example calculation show that significant periods of time are needed to reach complete neutralization and abundant precipitation of carbonates, zeolites, and smectites.

[24] Composition of aqueous solution (Figure 2c) is controlled by a dynamic balance between dissolution and precipitation. Dissolution of primary minerals increases concentrations of cations and neutral species (e.g., $\mathrm{SiO}_{2}$ ) until secondary phases form. Precipitation suppresses the increase of mineralization of solution and may cause a decrease in the concentration of solutes. For example, precipitation of silica and then silicates stabilizes the concentration of $\mathrm{SiO}_{2}(\mathrm{aq})$. Precipitation of goethite, kaolinite, $\mathrm{Fe}^{2+}$-saponite and $\mathrm{Mg}$-saponite causes a decrease in concentrations of $\mathrm{Fe}^{3+}, \mathrm{Al}^{3+}, \mathrm{Fe}^{2+}$, and $\mathrm{Mg}^{2+}$, respectively. At $\mathrm{pH}>\sim 6$, decreasing concentrations of $\mathrm{Ca}$ solutes reflect precipitation of zeolites and dolomite. Formation of stilbite and Na-bearing clays stabilize the concentration of $\mathrm{Na}$ solutes. Although $\mathrm{pH}$ increases with time, precipitation of kaolinite, $\mathrm{Fe}^{2+}$-saponite and dolomite stabilizes $\mathrm{pH}$ for long periods of time. Overall, solution evolves from $\mathrm{Mg}^{-\mathrm{Fe}^{2+}}$ $\mathrm{Fe}^{3+}-\mathrm{Al}-\mathrm{Ca}-\mathrm{CO}_{2}-\mathrm{SO}_{4}-\mathrm{Cl}$ acidic fluid toward an alkaline $\mathrm{Na}-\mathrm{SO}_{4}-\mathrm{Cl}-\mathrm{CO}_{3}$ composition, which is mostly controlled by dissolution of plagioclase and precipitation of phyllosilicates, zeolites, and carbonates. Concentrations of $\mathrm{HCO}_{3}^{-}$ and $\mathrm{CO}_{3}^{2-}$ ions increase in time, reflecting increasing solubility of atmospheric $\mathrm{CO}_{2}$ at higher $\mathrm{pH}$. In this example, elevated $W / R$ ratio and lack of evaporation and/or freezing prevents deposition of sulfates and chlorides, and concentrations of $\mathrm{S}^{6+}$-bearing solutes and $\mathrm{Cl}^{-}$do not change.

\subsection{Effects of Water/Rock Ratio, Grain Size, Degree of Exposure, Initial $\mathrm{pH}$, and $\mathrm{O}_{2}$ Pressure}

[25] Modeling shows that patterns of $\mathrm{pH}$ change and sequence of mineral precipitation are not strongly affected by the water/rock mass ratio in the range of $0.01-100$ 

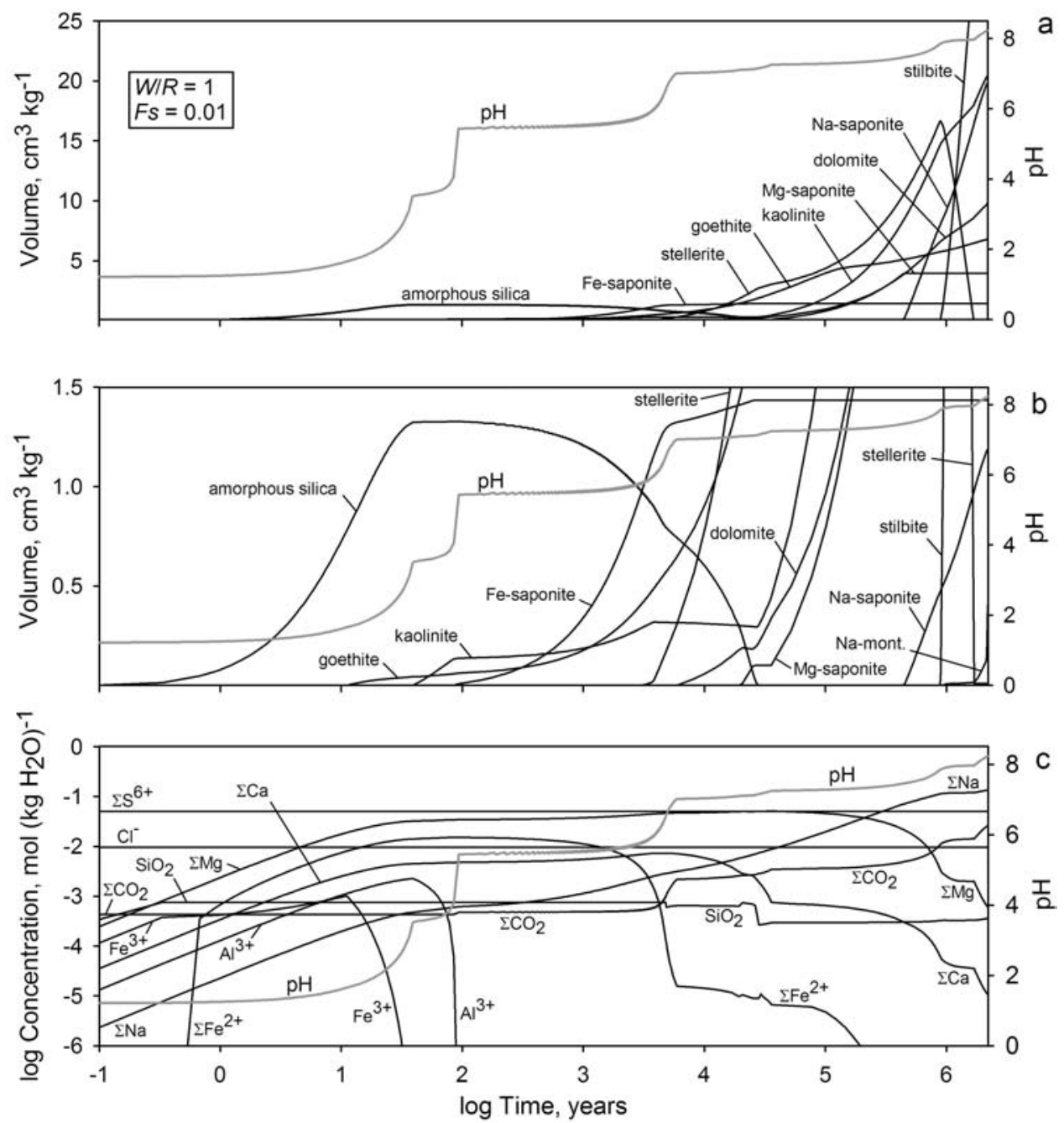

Figure 2. (a, b) Volumes of secondary minerals and (c) the composition of aqueous solution during acid weathering of olivine basalt. Different vertical scales are used in Figures $2 \mathrm{a}$ and $2 \mathrm{~b}$. Parameters of alteration are described in the caption of Figure 1. In Figure 2c, concentration of dissolved $\mathrm{O}_{2}$ is $\sim 1.6 \times 10^{-8} \mathrm{~mol} \mathrm{~kg}^{-1} . \Sigma \mathrm{CO}_{2}=\Sigma\left(\mathrm{CO}_{2}, \mathrm{HCO}_{3}{ }^{-}, \mathrm{CO}_{3}{ }^{2-}, \mathrm{CaHCO}_{3}{ }^{+}, \mathrm{MgHCO}_{3}{ }^{+}\right) ; \Sigma \mathrm{S}^{6+}=\Sigma\left(\mathrm{SO}_{4}{ }^{2-}\right.$, $\left.\mathrm{HSO}_{4}{ }^{-}, \mathrm{MgSO}_{4}, \mathrm{CaSO}_{4}, \mathrm{NaSO}_{4}{ }^{-}\right) ; \Sigma \mathrm{Mg}=\Sigma\left(\mathrm{Mg}^{2+}, \mathrm{MgSO}_{4}, \mathrm{MgHCO}_{3}^{+}, \mathrm{MgHSiO}_{3}{ }^{+}\right) ; \Sigma \mathrm{Ca}=\Sigma\left(\mathrm{Ca}^{2+}\right.$, $\left.\mathrm{CaSO}_{4}, \mathrm{CaHCO}_{3}{ }^{+}\right) ; \Sigma \mathrm{Fe}^{2+}=\Sigma\left(\mathrm{Fe}^{2+}, \mathrm{HFeO}_{2}{ }^{-}\right) ; \Sigma \mathrm{Na}=\Sigma\left(\mathrm{Na}^{+}, \mathrm{NaSO}_{4}{ }^{-}, \mathrm{NaHSiO}_{3}\right)$. See color version of this figure in the HTML.

where "water" represents $\mathrm{H}_{2} \mathrm{SO}_{4}-\mathrm{HCl}$ solution. Rates of dissolution are not directly influenced by $W / R$ ratio. However, $W / R$ ratio influences the timing of neutralization and saturation of solution with respect to secondary phases. For some minerals (silica, kaolinite, $\mathrm{Fe}^{2+}$-saponite), time of precipitation is roughly proportional to $W / R$ ratio. At the same original $\mathrm{pH}$, higher $W / R$ ratios cause slower neutralization and late precipitation of secondary minerals (Figures 3 and 4). In contrast, low $W / R$ ratios cause faster neutralization and can lead to a diverse assemblage of secondary minerals during short-duration acid weathering. Weathering at small $W / R$ ratios also causes precipitation of some minerals (daphnite, siderite, calcite) that do not form at elevated $W / R$. However, in these cases, amounts of secondary phases are small and most of the initial minerals remains unaltered. Evidently, weathering is fastest if a small amount of low-pH solution interacts with completely exposed dust-size particles (Figure 4).
[26] Increasing grain sizes and decreasing mineral exposure produce smaller effective surface areas and lead to similar effects as an increase in $W / R$ ratio. Timing of neutralization and deposition of major secondary phases is proportional to primary mineral grain sizes (Figure 5). However, at small grain sizes, some secondary minerals (dolomite, daphnite, siderite) tend to precipitate earlier at lower $\mathrm{pH}$. Timing of secondary deposition is proportional to the degree of grain exposure with the exception of daphnite, dolomite, and $\mathrm{Mg}$-saponite, which form relatively early at lower $\mathrm{pH}$ near well-exposed mineral grains $\left(F_{S}>0.1\right)$, as can be seen in Figure 6. Daphnite may not precipitate during weathering of grains with diameter $>\sim 0.1 \mathrm{~mm}$, at low degrees of exposure, and at high $W / R$ ratios (Figures 2-6). However, daphnite is the major ferrous phyllosilicate that forms through weathering of fine particles by low amounts of acid fluids, which may represent acids attacks on typical Martian soil (Figure 7). 


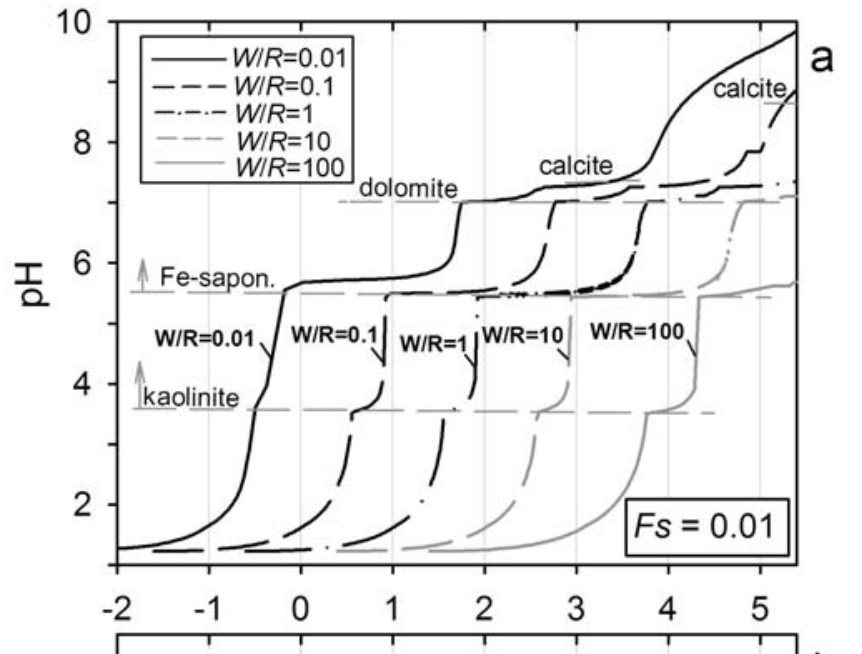

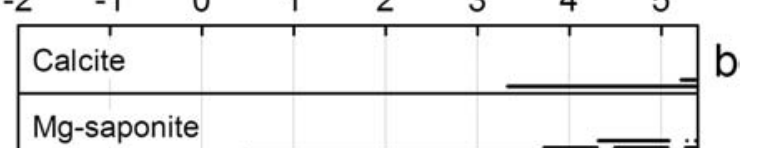

\begin{tabular}{|l|}
\hline Na-montmorillonite \\
\hline Na-saponite \\
\hline Fe-saponite
\end{tabular}

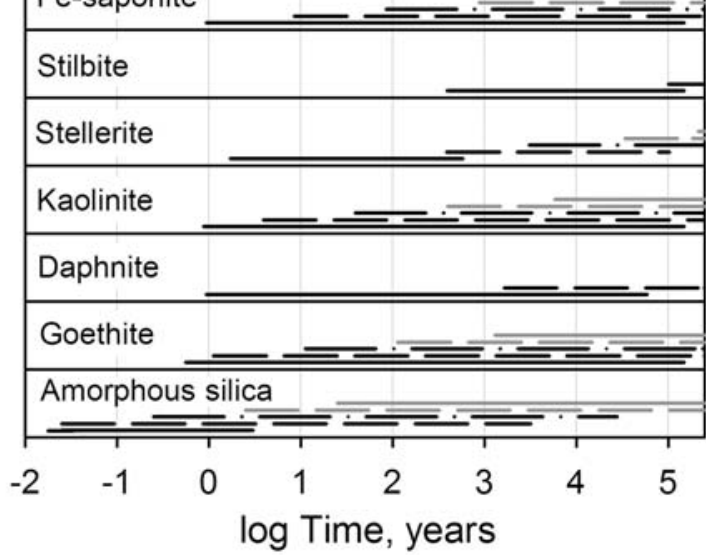

Figure 3. (a) Effects of initial water/rock mass ratio on $\mathrm{pH}$ and (b) secondary mineralogy during acid weathering of olivine basalt. Other parameters of weathering are the same as for Figure 1. In Figure 3a, grey dashed lines with arrows show precipitation conditions of some minerals. In Figure $3 \mathrm{~b}$, horizontal lines depict time intervals at which minerals are present in altered rocks at different $W / R$ ratios. See color version of this figure in the HTML.

[27] Initial solution $\mathrm{pH}$ has a moderate effect on the general sequence of mineral precipitation, but significantly affects timing of precipitation and neutralization. Weathering by solutions with initial $\mathrm{pH}$ of $0-2$ causes very early precipitation of amorphous silica followed by the formation of gypsum (Figure 8). Higher initial pH causes later precipitation of silica and earlier formation of goethite, phyllosilicates and carbonates. If original $\mathrm{pH}>2-3$, amorphous silica does not form and aluminosilicates precipitate earlier than in systems with lower original $\mathrm{pH}$. If original

$\mathrm{pH}>\sim 2$, goethite can form before silica. Goethite precipitates earlier at higher initial $\mathrm{pH}$.

[28] Variations in $P_{\mathrm{O}_{2}}$ affect $\mathrm{pH}$, timing of mineral precipitation, and amounts of goethite and ferrous aluminosilicates as illustrated in Figures 9 and 10. At $P_{\mathrm{O}_{2}}<\sim 10^{-4}$ bar, which characterizes present and past Martian surface conditions, formation of goethite is accompanied by deposition of ferrous phyllosilicates $\left(\mathrm{Fe}^{2+}\right.$-saponite, daphnite). Siderite can also form at late stages of weathering of fine particles at low $W / R$ ratios and then subjected to dissolution (and oxidation) (Figures 4, 5b, and 7a). At $P_{\mathrm{O}_{2}}<\sim 10^{-7}$ bar formation of goethite is mostly accounted for by the supply of $\mathrm{Fe}^{3+}$ from dissolving magnetite (Figures 9 and 10). At the $P_{\mathrm{O}_{2}}$ of present Martian atmosphere $\left(\sim 10^{-5}\right.$ bar $)$, only minor amount of goethite forms if magnetite is not present (Figures $7 b$ and 9).

[29] Formation of nontronite, a $\mathrm{Fe}^{3+}$-bearing smectite, has not been observed. Formation of ferric aluminosilicates requires a specific array of activities of $\mathrm{Fe}^{3+}, \mathrm{Al}^{3+}$ and $\mathrm{SiO}_{2}(\mathrm{aq})$, which is probably less likely than reaching saturation with respect to ferric hydroxide. Formation of $\mathrm{K}-\mathrm{Na}-\mathrm{H}_{3} \mathrm{O}$ jarosites have not been observed. Formation of jarosite requires low $W / R$ ratios [e.g., Zolotov and Shock, 2005] that do not represent many of our models. These results demonstrate that goethite is more stable than jarosite. Observed precipitation of goethite instead of hematite is consistent with higher stability of goethite in low-temperature solutions that have high $(\sim 1)$ activity of water.

\subsection{Freezing and Evaporation of Weathering Solutions}

[30] We modeled equilibrium freezing of typical solutions that represented various stages of acid weathering (Table 3).

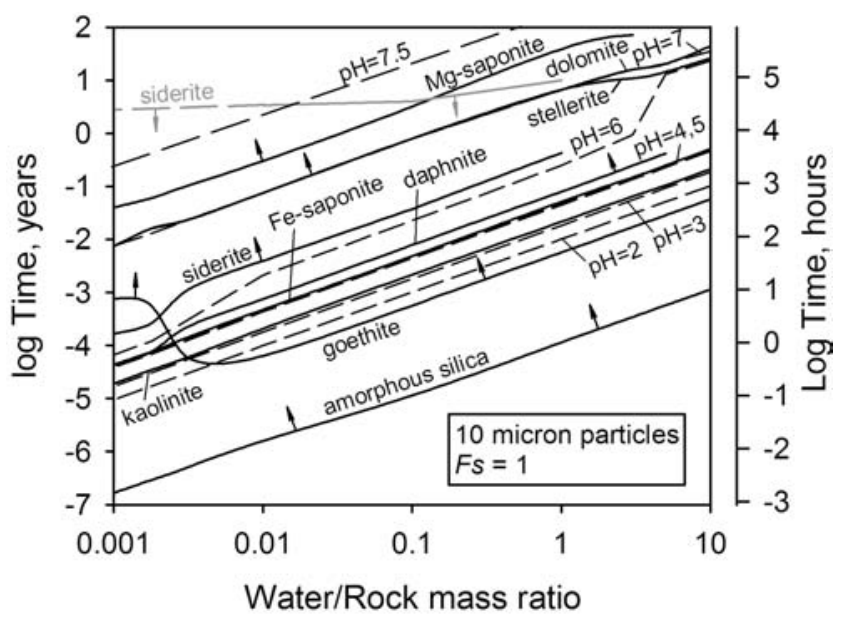

Figure 4. Effects of water/rock mass ratio on time of secondary precipitation during acid weathering of basaltic dust. The dust is presented by 10 -micron monomineral silicate particles and 2.5-micron magnetite grains that are fully exposed to solution. Other parameters of weathering are the same as for Figure 1. The dashed lines correspond to time at which specific $\mathrm{pH}$ is achieved. The lines with arrows show times of first deposition of secondary minerals. The arrows point toward field of conditions at which secondary phases form. Note that siderite dissolves at higher $\mathrm{pH}$ and the grey line shows the conditions of its complete dissolution. See color version of this figure in the HTML. 

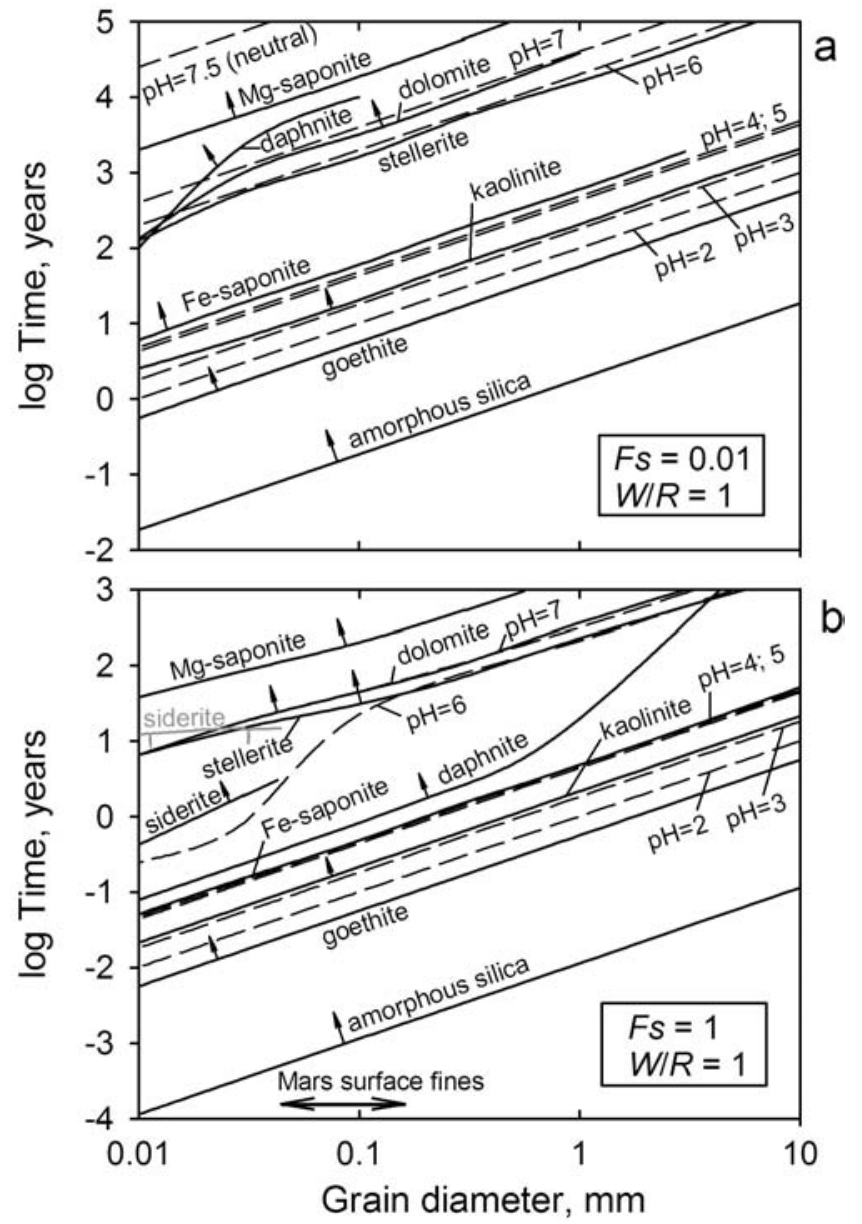

Figure 5. Effect of grain size of primary minerals of olivine basalt on timing of neutralization and deposition of secondary minerals during acid weathering. (a) One percent of mineral grains is exposed for solution $\left(F_{S}=0.01\right)$. (b) Particles are fully exposed to solution $\left(F_{S}=1\right)$. Other parameters are the same as for Figure 1. The dashed lines correspond to time at which specific $\mathrm{pH}$ is achieved. The lines with arrows show times of first deposition of secondary minerals. The grey curve shows the conditions of complete dissolution of siderite. The grain size on $x$ axis corresponds to the diameter of spherical silicate grains, the diameter of magnetite grains is 4 times less. The double arrow shows the range of particle size in Martian soils from Fergason et al. [2006]. The grain size of the atmospheric dust is $0.2-10$ micron. See color version of this figure in the HTML.

Complete freezing of acidic solutions leads to the formation of abundant hydrated $\mathrm{Mg}$ sulfates, hydrated $\mathrm{Mg}$ chloride, gypsum, and silica. Freezing of solutions with initial $\mathrm{pH}<\sim 5.5$ causes deposition of melanterite, $\mathrm{FeSO}_{4} \cdot 7 \mathrm{H}_{2} \mathrm{O}$. The formation of ferrous sulfate reflects the predominance of $\mathrm{Fe}^{2+}$ over $\mathrm{Fe}^{3+}$ in solutions (except very early stages of weathering, Figure 2c). Freezing of solution with $\mathrm{pH} \sim 7$ causes precipitation of tiny amounts of siderite and hydromagnesite. Sodium sulfate (mirabilite) and chloride (hydrohalite) become increasingly abundant precipitants from initial solutions with higher $\mathrm{pH}$, which represent advanced stages of weathering. Freezing of slightly alkaline fluids causes precipitation of abundant $\mathrm{Na}$ salts (mirabilite, natron, hydrohalite) while $\mathrm{Mg}$ sulfates and chlorides do not form. The deposition of abundant carbonates from alkaline solutions is accounted for by increased solubility of atmospheric $\mathrm{CO}_{2}$. Compared to high-pH solutions, the amounts of precipitated hydroxides and/or oxyhydroxides of $\mathrm{Fe}^{3+}$ and $\mathrm{Al}^{3+}$ are significantly larger during freezing of fluids with $\mathrm{pH}$ below $\sim 2$ and $\sim 4$, respectively.

[31] The sequence of precipitation during freezing reflects the solubility of solids and initial solution composition. An early precipitation of gypsum, $\mathrm{SiO}_{2}, \mathrm{Fe}^{3+}$ and $\mathrm{Al}^{3+}$ hydroxides, and carbonates (from high-pH solutions) is followed by the formation of $\mathrm{Mg}$ and $\mathrm{Fe}$ sulfates and then $\mathrm{Mg}$ and $\mathrm{Na}$ chlorides (Figure 11a and Table 3). Although sulfate and chloride ions have a tendency to accumulate in the aqueous phase, evolution of solution composition reflects the pattern of precipitation (Figure 11b).

[32] Freezing of acid fluids is accompanied by the accumulation of protons in solution that may lead to the formation of acid hydrates and acid salts at eutectics. For example, freezing of solution with $\mathrm{pH} 1.6$ causes formation of solid $\mathrm{H}_{2} \mathrm{SO}_{4}$ hydrate, which is more abundant than $\mathrm{Mg}$ sulfate (Figure 11a and Table 3). An exotic Na sulfate, $\mathrm{Na}_{3} \mathrm{H}\left(\mathrm{SO}_{4}\right)_{2}$, forms at $\mathrm{pH}-1.26$. The calculated eutectic temperature, at which $\mathrm{H}_{2} \mathrm{SO}_{4} \cdot 6.5 \mathrm{H}_{2} \mathrm{O}$ forms, is $-64.4^{\circ} \mathrm{C}$, close to the average temperature of Martian surface $\left(-63^{\circ} \mathrm{C}\right)$. High concentrations of $\mathrm{H}^{+}$in our initial solutions could be primarily responsible for lowering eutectic temperatures. Higher initial $\mathrm{pH}$ causes freezing at higher temperatures (Table 3).

[33] Evaporation of acid solutions at $0^{\circ} \mathrm{C}$ leads to the formation of abundant hydrated $\mathrm{Mg}$ sulfate (epsomite), $\mathrm{Fe}^{2+}$ salts (melanterite), and Ca sulfates (Figure 12). Evaporation

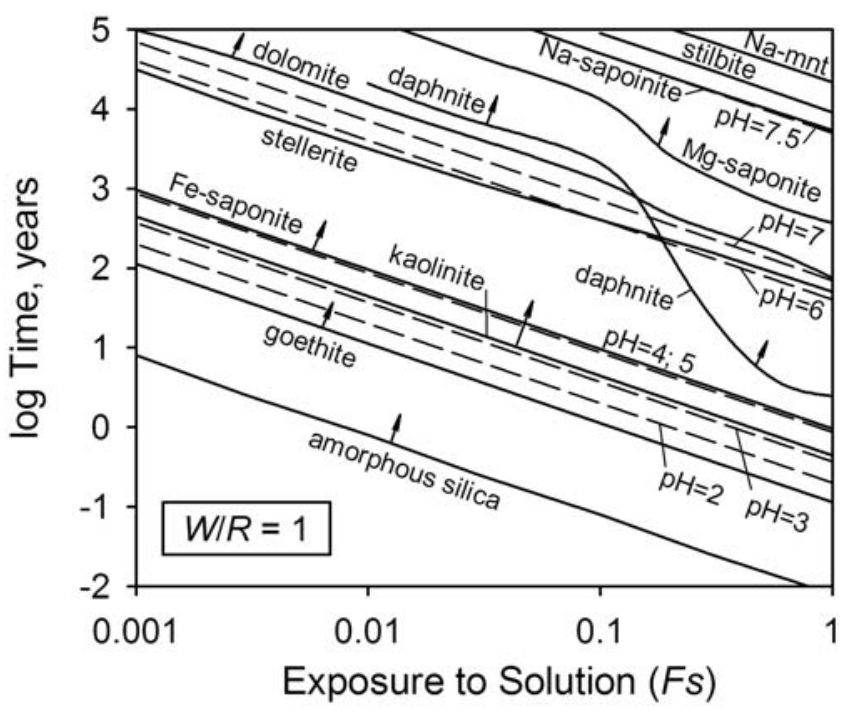

Figure 6. Effect of exposure of primary mineral grains $(F s)$ of olivine basalt on timing of neutralization and deposition of secondary phases. Other parameters of weathering are the same as for Figure 1. Parameter $F_{S}$ is taken to be the same for all minerals. The dashed lines correspond to time at which specific $\mathrm{pH}$ is achieved. See color version of this figure in the HTML. 


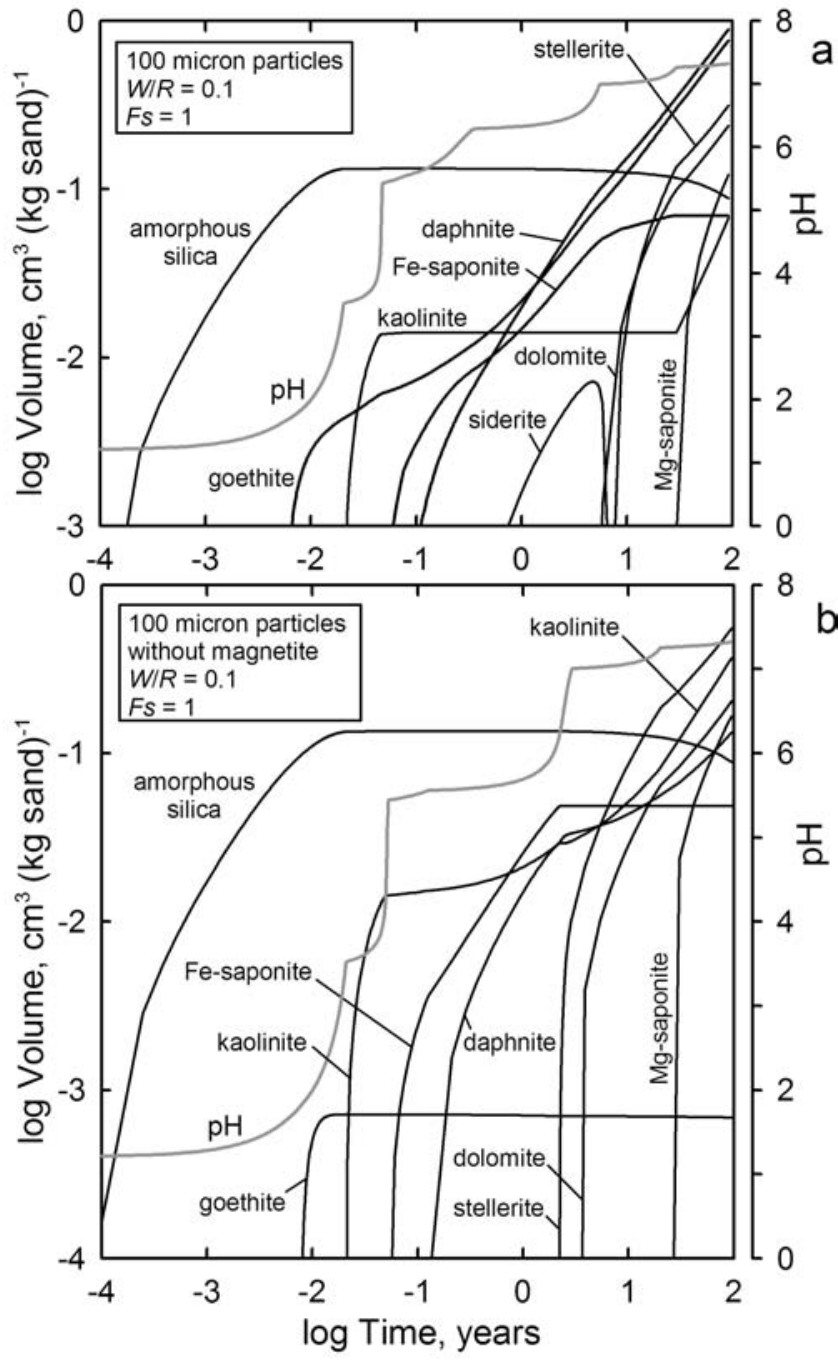

Figure 7. Volumes of secondary phases and $\mathrm{pH}$ during acid weathering of fine olivine basalt sand at $W / R=0.1$ and complete exposure of particles to solution. Grain size of silicates is 100 micron; magnetite, 25 micron. The grain size of silicates is typical for Martian soil [Fergason et al., 2006] and represents the most wind-movable grain fraction [Greeley et al., 1980]. In Figure 7b, dissolution of magnetite was suppressed to illustrate weathering of basalt without magnetite. Other parameters are the same as for Figure 1. Note that silica precipitates very early (in $\sim 2$ hours) and that very small volumes of secondary phases form. Comparison of Figures $7 \mathrm{a}$ and $7 \mathrm{~b}$ indicates a major contribution of magnetite weathering in goethite formation. See color version of this figure in the HTML.

of solution with $\mathrm{pH} 1.61$ causes decrease in $\mathrm{pH}$ below -1 and preferential accumulation of $\mathrm{Cl}^{-}$and $\mathrm{SO}_{4}^{2-}$ in solution. Modeling shows a tendency for dehydration of early formed sulfates in very concentrated solutions. However, the fate of concentrated acid solution is unclear because of high $a \mathrm{H}^{+}$and the uncertainty of thermodynamic data for $\mathrm{H}_{2} \mathrm{SO}_{4} \cdot 4 \mathrm{H}_{2} \mathrm{O}$ at $0^{\circ} \mathrm{C}$ [Marion, 2002]. Current data do not exclude that $\mathrm{H}_{2} \mathrm{SO}_{4} \cdot 4 \mathrm{H}_{2} \mathrm{O}$ is stable among phases formed at complete evaporation. Note that our models refer to evaporation and freezing of solution that does not interact

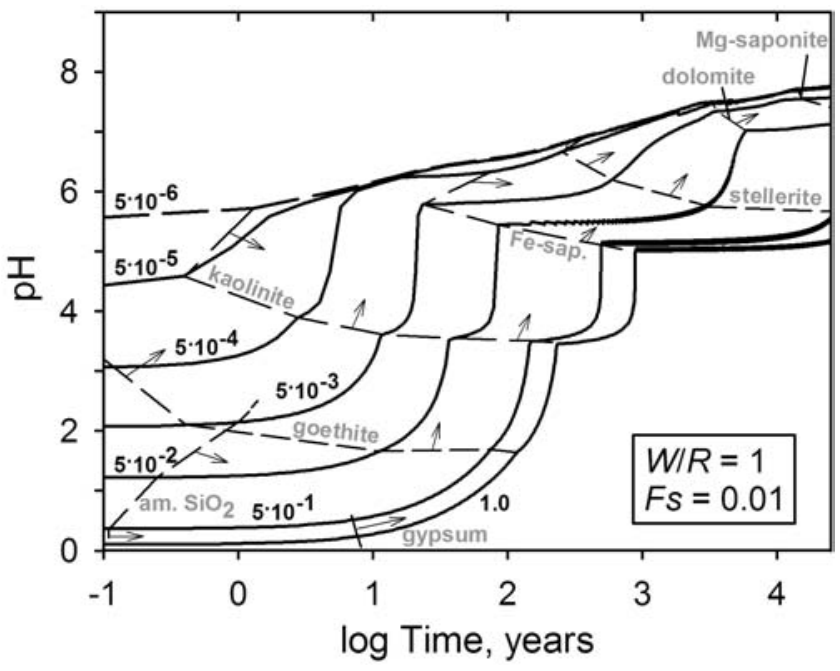

Figure 8. Temporal changes in $\mathrm{pH}$ during weathering of olivine basalt for solutions with various initial concentrations of $\mathrm{H}_{2} \mathrm{SO}_{4}$ and $\mathrm{HCl}$. Other parameters are the same as for Figure 1. Numbers at each curve corresponds to the molar amount of $\mathrm{H}_{2} \mathrm{SO}_{4}$ per $\mathrm{kg}$ of water in original solutions. For each solution, $\mathrm{H}_{2} \mathrm{SO}_{4} / \mathrm{HCl}$ molar ratio is 5.2. Dashed lines show $\mathrm{pH}$ and time of first precipitation of some minerals. Arrows at these lines point toward field of conditions at which minerals form. See color version of this figure in the HTML.

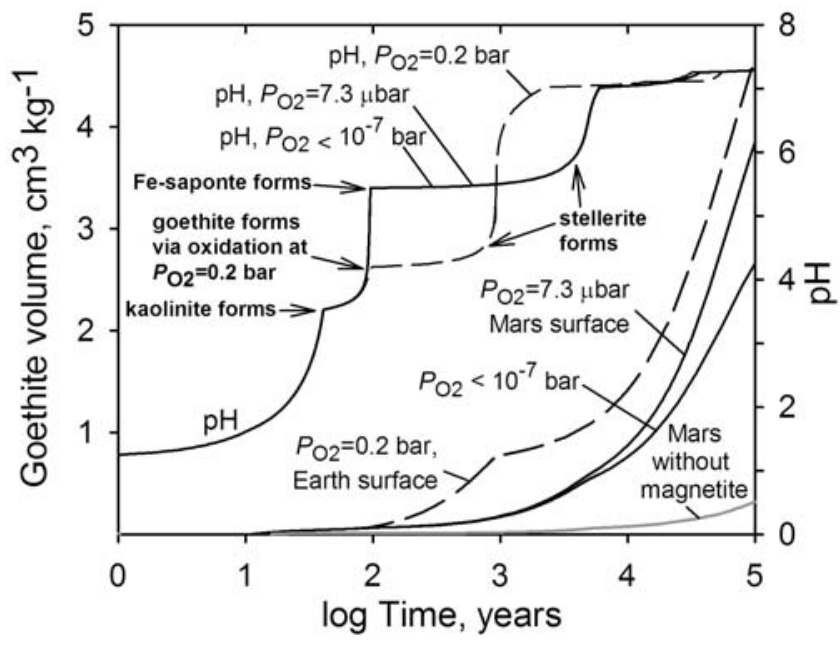

Figure 9. Volumes of secondary goethite and $\mathrm{pH}$ during acid weathering of olivine basalt at various partial pressures of $\mathrm{O}_{2}$. Other parameters are the same as for Figure 1. Mars surface conditions are represented by $P_{\mathrm{O}_{2}}=7.3 \mu \mathrm{bar}$, Mars subsurface or "volcanic" atmosphere is characterized by $P_{\mathrm{O}_{2}}<\sim 10^{-7}$ bar, and Earth's surface conditions correspond to $P_{\mathrm{O}_{2}}=0.2$ bar. The grey curve shows the volume of goethite that forms at current Martian $P_{\mathrm{O}_{2}}$ if magnetite is not present. Goethite does not form before time of 10 years; the time interval of $10-100$ years is characterized by the formation of a tiny amount of goethite through dissolution of magnetite. After $\sim 10^{2}$ years, the formation of goethite occurs via the dissolution of magnetite and aqueous oxidation of $\mathrm{Fe}^{2+}$. Dissolution of magnetite provides the major source of goethite at current Martian $P_{\mathrm{O}_{2}}$. See color version of this figure in the HTML. 

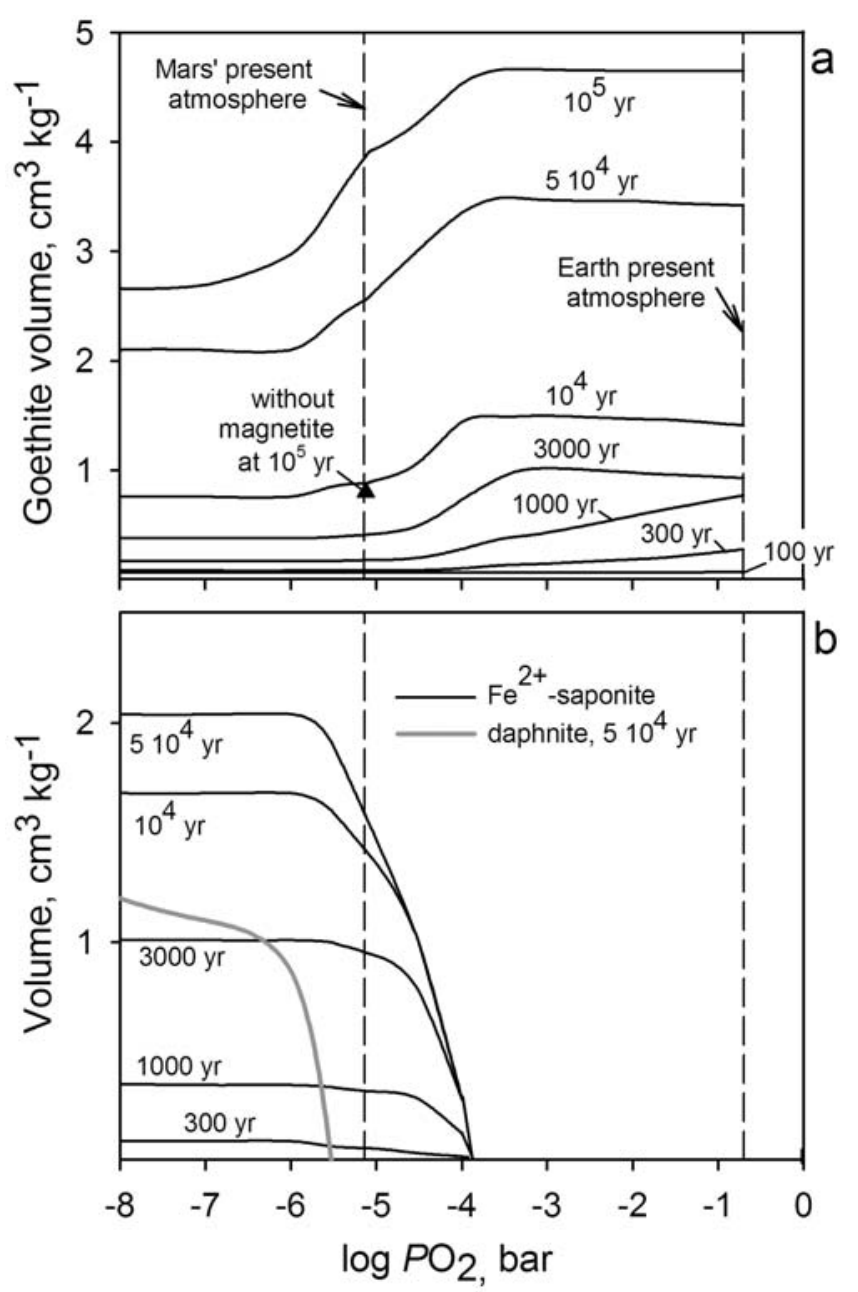

Figure 10. Volumes of (a) goethite and (b) $\mathrm{Fe}^{2+}$-saponite and daphnite formed during acid weathering of olivine basalt as functions of $P_{\mathrm{O}_{2}}$. Other parameters are the same as for Figure 1. Each curve represents different time since the beginning of acid weathering. The vertical dashed lines show $P_{\mathrm{O}_{2}}$ in present Mars' and Earth's atmospheres. In Figure $10 \mathrm{a}$, the triangle depicts the amount of goethite formed by $10^{5}$ years in a magnetite free rock. Below $P_{\mathrm{O}_{2}}$ of $\sim 10^{-7}$, the accumulation of goethite in time is accounted for by the dissolution of magnetite. At elevated $P_{\mathrm{O}_{2}}$, the increase in goethite volumes in time is also due to oxidation of $\mathrm{Fe}^{2+}$. Ferrous silicates do not form at $P_{\mathrm{O}_{2}}>10^{-4}$ bar. At $P_{\mathrm{O}_{2}}<10^{-4}$ bar, $\mathrm{Fe}^{2+}$-saponite and daphnite form together with goethite.

with minerals. In the latter case, aggressive low-pH weathering and some neutralization is expected.

\section{Discussion}

[34] Chemical weathering is seen as an irreversible, nonequilibrium, stochastic process, which implies the necessity of stepwise modeling. At early stages, the process is governed by the dissolution of primary minerals, which remains the limiting step throughout alteration. A pathway of further weathering is governed by a delicate balance between mineral dissolution, precipitation of secondary phases, and oxidation of $\mathrm{Fe}^{2+}$, which are connected by feedbacks. Dissolution of minerals increases $\mathrm{pH}$, which often leads to lower dissolution rates. Increasing concentrations of solutes causes minerals to precipitate, which can stabilize the composition of solution. Precipitation also regulates $\mathrm{pH}$ and dissolution rates. Although higher $\mathrm{pH}(>\sim 3.5)$ increases the rate of $\mathrm{Fe}^{2+}$ oxidation, formation of ferric species releases $\mathrm{H}^{+}$ (e.g., Reaction 7) partially compensating for rising $\mathrm{pH}$. Significant increases in $\mathrm{pH}$ related to the formation of zeolites lowers dissolution rates of ferrous minerals and limits the amount of precipitated goethite.

[35] Despite these compensatory effects, overall decreasing acidity reduces rates of mineral dissolution and makes weathering less efficient in time. A stepwise quasiexponential slowing of weathering can be seen in Figures 1-8. In fact, the major events (formation of amorphous silica, goethite, kaolinite, and smectites) occur early and time intervals between depositions of each new phase grow sequentially. Rapid neutralization and corresponding decrease
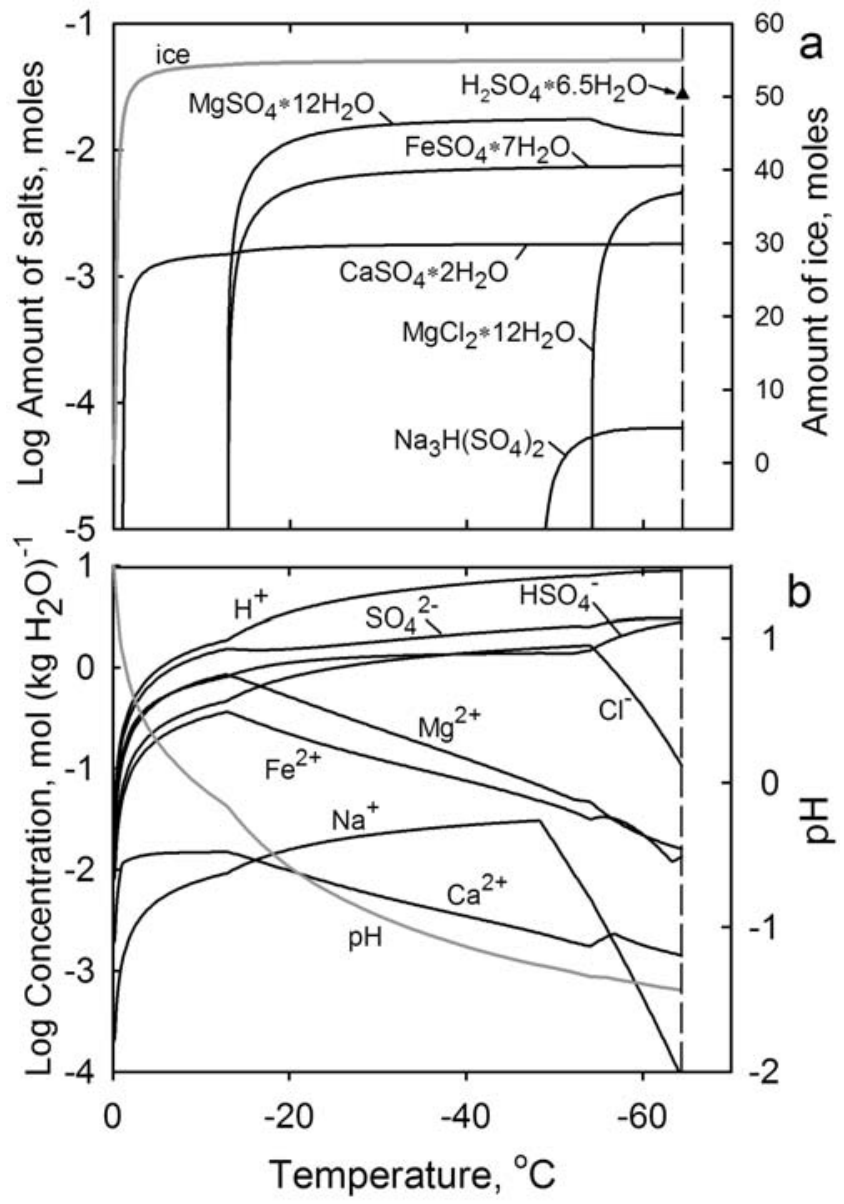

Figure 11. (a) Precipitation of solids and (b) concentrations of aqueous species during equilibrium freezing of the solution formed at an early stage of acid weathering of olivine basalt. The starting solution containing $1 \mathrm{~kg}$ of water (55.508 moles) corresponds to the time of 10.1 years at Figure $2 \mathrm{c}$ and has $\mathrm{pH}$ 1.61. The dashed vertical lines correspond to eutectic temperature. The eutectic composition is also shown in Table 3. See color version of this figure in the HTML. 


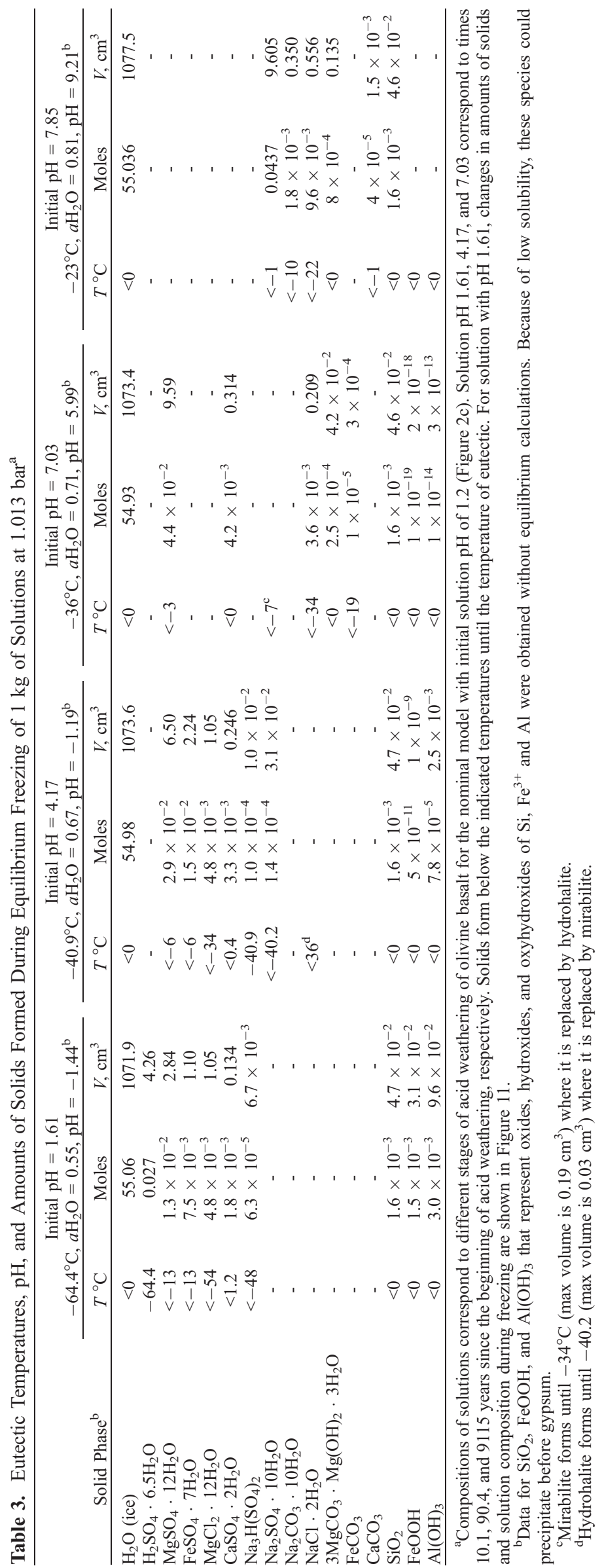




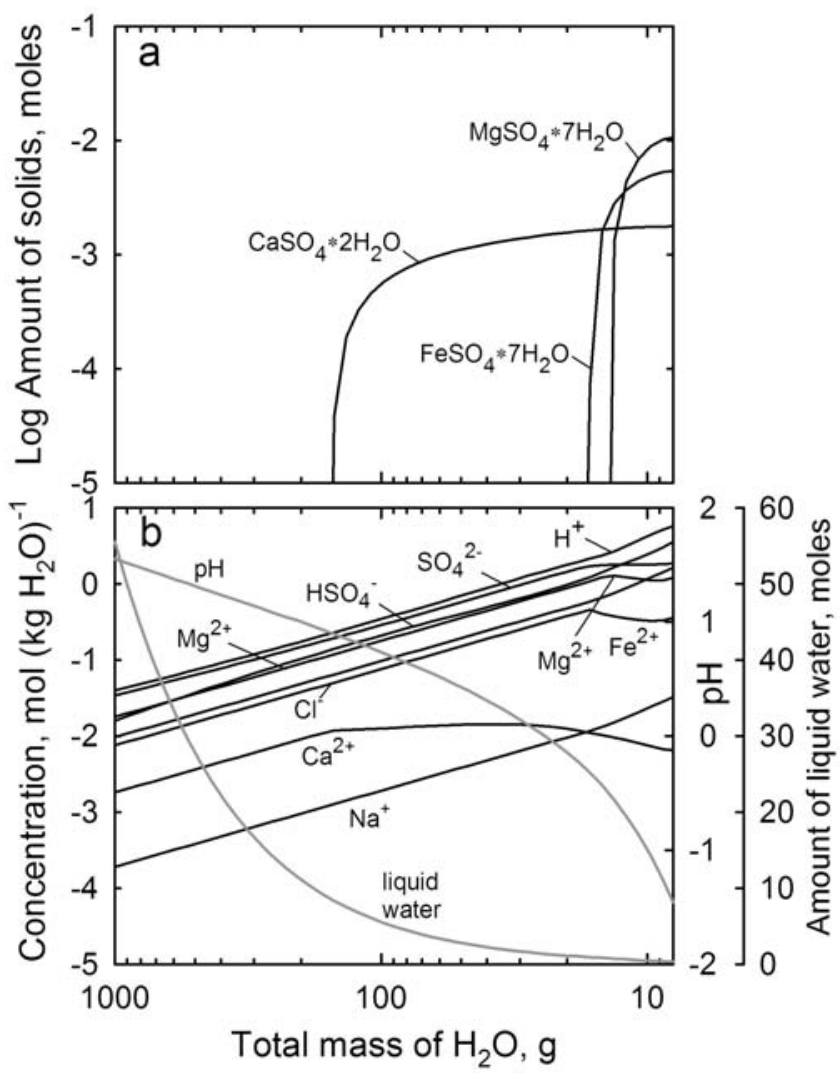

Figure 12. (a) Amounts of precipitated solids and (b) concentrations of aqueous species during incomplete equilibrium evaporation $\left(\right.$ at $0^{\circ} \mathrm{C}$ ) of the solution formed at an early stage of acid weathering of olivine basalt. The starting solution is the same as for Figure 11. Although further evolution of solution is not shown (see text), it may include dehydration and dissolution of precipitates at extremely low $\mathrm{pH}$. See color version of this figure in the HTML.

in dissolution rates work toward preservation of primary minerals. For typical basaltic lava, a complete closed system equilibration at low-temperature aqueous conditions could not be achieved even over geological timescale (Figures 1-3). Short-term episodes of acid weathering do not affect the majority of large rock fragments and the process may end before precipitation of clays, zeolites, and carbonates. This inference is strengthened by typically lower rates of natural weathering compared to laboratory data [e.g., White and Brantley, 2003] used in modeling.

\subsection{Fate of Primary Minerals in Weathering Models and Martian Materials}

[36] Different $\mathrm{pH}$ dependencies of mineral dissolution rates (Table 2) imply preferential dissolution of specific primary phases at each weathering stage (Figure 1b). It follows that abundances of primary minerals in a weathered material could reflect a stage of alteration. Our results show that basalt weathered below $\mathrm{pH} \sim 3$ would be enriched in plagioclases that dissolve slower than olivine, Fe-Mg pyroxenes and magnetite.

[37] On the Martian surface, variations in abundances of primary basaltic minerals could reflect preferential dissolu- tion of some phases. The interpretation of thermal emission spectra (TES) of low-albedo surface regions reveals broad variations in the pyroxene/plagioclase ratio (0.16 to 1.24$)$ [Bandfield et al., 2000; Bandfield, 2002; Hamilton et al., 2001; Wyatt and McSween, 2002; McSween et al., 2003; Michalski et al., 2006a; Rogers et al., 2007], which may not be entirely related to igneous petrology. Lowest pyroxene/ plagioclase ratios are observed in the Northern hemisphere, for example, in Acidalia Planitia (surface type 2 [Bandfield et al., 2000; Bandfield, 2002; Christensen et al., 2001a]). These observations are consistent with faint pyroxene features in near-infrared spectra of northern low-albedo regions [Bibring et al., 2005; Mustard et al., 2005; Mustard and Cooper, 2005]. A kinetic modeling in the pyroxeneplagioclase system open to solution [McAdam et al., 2007a], and our results suggest that the observed deficiency of pyroxene could be related with aqueous weathering below $\mathrm{pH}$ 3. In Gusev crater, depletion of rock surfaces in $\mathrm{Mg}$ and $\mathrm{Fe}$ in the Clovis class rocks may indicate preferential low$\mathrm{pH}$ dissolution of pyroxene and olivine relative to feldspars [Hurowitz et al., 2006]. In heavily altered Wishstone class rocks, the high Na-plagioclase/pyroxene ratio (4-5 [Ruff et al., 2006]) may reveal faster dissolution of pyroxene. A presence of plagioclase in heavily altered jarosite-bearing bedrocks in Meridiani Planum [Glotch et al., 2006] also agrees with its slow low-pH alteration compared to primary $\mathrm{Fe}-\mathrm{Mg}$ silicates that are not detected in the bedrocks. A high plagioclase/pyroxene ratio inferred from TES spectra of Martian dust [e.g., Bandfield and Smith, 2003] is also consistent with preferable pyroxene alteration (A. C. McAdam et al., Preferential low-pH dissolution of pyroxene in plagioclase-pyroxene mixtures: Implications for Martian surface materials, submitted to Icarus, 2007). Since the spectral data refer to surfaces on mineral grains, the bulk pyroxene/plagioclase ratio in surface materials may not be strongly affected by weathering. It is possible that observed weak pyroxene signatures are related to specifics of surface alteration of pyroxene and/or silica coatings [Rampe et al., 2006] (see section 4.2).

[38] The presence of magnetite in Martian soil [Morris et al., 2006] and atmospheric dust [Pollack et al., 1979; Goetz et al., 2005] is not consistent with weathering above $\mathrm{pH} 3-5$ when magnetite may dissolve faster than silicates (Figure 1b). Weathering of magnetite could have been slowed because of a presence of $\mathrm{Ti}$ [White et al., 1994], a resistance to physical weathering, and secondary $\mathrm{Fe}^{3+}$ oxide coatings, consistent with reddish hue of magnetite-rich dust particles accumulated on MER magnets [Goetz et al., 2005].

\subsection{Secondary Silica}

[39] The models show that formation of amorphous silica may designate early stages of basalt weathering by solutions with initial $\mathrm{pH}$ below $\sim 3$. Neutralization of these solutions above $\mathrm{pH} 3$ may cause dissolution of silica. Our results agree with the formation of amorphous silica in experiments aimed to model acid weathering of basalts [Tosca et al., 2004; Golden et al., 2005; Hurowitz et al., 2005] and at volcanic locations affected by acid vapors and solutions [Golden et al., 1993; Wolfe et al., 1997; Morris et al., 2000; Schiffman et al., 2006]. An early formation of silica is also inferred from thermodynamic models for acid weathering [Schiffman et al., 2006; McAdam et al., 2007b]. These 
observations and models are consistent with low solubility and slow dissolution of amorphous silica in acids [Dove and Rimstidt, 1994; Dove, 1995].

[40] Secondary silica has been reported in the ALH84001 Martian meteorite where it forms veins and coatings probably deposited from low- $T$ aqueous solutions [Westall et al., 1998; McKay et al., 1998]. A likely presence of amorphous silica in surface materials became evident from thermal infrared spectra obtained from the orbit and at MER sites. Indistinguishable "high-silica phases" observed in spectra of some low-albedo regions (surface-type 2) may contain amorphous silica formed through basalt alteration [Wyatt and McSween, 2002; Kraft et al., 2003; Michalski et al., 2005]. Laboratory investigations show that thermal infrared observations could be explained by silica coating on primary mineral grains [Kraft et al., 2003; Rampe et al., 2006]. Abundant (up to 25 vol.\%) silica-rich glass and/or impure amorphous silica in layered bedrocks in Meridiani Planum [Glotch et al., 2006] is consistent with acid environments. At the Columbia Hills in Gusev crater, some rock classes (Clovis, Watchtower) may contain high-silica glass [Ruff et al., 2006] that may represent weathering products. The elemental composition of trench soils in Gusev crater indicates a presence of silica [Haskin et al., 2005]. At the Mars Pathfinder landing site, elevated Si content in rock fragments may represent secondary silica on basaltic rock fragments [McLennan, 2003; Hurowitz et al., 2006] that contributes to the observed "andesitic" bulk composition [Foley et al., 2003]. If confirmed, the presence of amorphous $\mathrm{SiO}_{2}$ in Martian surface materials would be consistent with low-pH environments and a lack of thorough neutralization of aqueous solutions in many locations.

[41] Since the formation of silica coatings on primary minerals decreases their dissolution rates, chemical or mechanical removal of coatings could be needed to facilitate alteration. Silica coatings could be weaken through neutralization of solution, alteration by solution with $\mathrm{pH}>3$, as well as physical weathering during and between episodes of aqueous weathering. Note that experimental data [Tosca et al., 2004; Golden et al., 2005; Hurowitz et al., 2006] and field observations [Schiffman et al., 2006] do not reveal a significant lingering of acid weathering because of silica coating.

\subsection{Fate of Ferrous Iron During Martian Weathering}

[42] Ferrous minerals on the Martian surface have been subjected to irreversible but limited oxidation. Although Martian surface materials contain several ferric phases (nanophase oxides, goethite, hematite, jarosite, and nontronite [Morris et al., 2000, 2006; Klingelhöfer et al., 2004; Poulet et al., 2005; Glotch et al., 2006]), ferrous minerals typically dominate in rock fragments and soils. The presence of magnetite in dust [Pollack et al., 1979; Goetz et al., 2005] and soil [Morris et al., 2006], and olivine and pyroxenes in rock fragments and soils [e.g., Klingelhöfer et al., 2004; Morris et al., 2006; Mustard et al., 2005; Hoefen et al., 2003] are consistent with only partial oxidation of primary minerals. Throughout history, aqueous $\mathrm{Fe}^{2+}$ oxidation at the surface could have been restricted by rare and short appearances of aqueous solutions [Haberle, 1998], and slow oxidation in acidic and $\mathrm{O}_{2}$-deficient environments [Burns, 1993; Hurowitz et al., 2006] (see also our results). Likewise, anhydrous photooxidation of ferrous minerals could have not been efficient [Morris and Lauer, 1980].

[43] At $P_{\mathrm{O}_{2}}<\sim 10^{-7}$ bar, which could represent Martian atmosphere during active volcanism [Catling and Moore, 2003], the role of $\mathrm{Fe}^{2+}$ oxidation is negligible and dissolution of $\mathrm{Fe}^{3+}$ spinels provided the major source for secondary $\mathrm{Fe}^{3+}$ species. The incongruent dissolution of magnetite in acid solutions leads to the formation of metastable maghemite [White et al., 1994],

$$
\left.\mathrm{Fe}_{3} \mathrm{O}_{4}+2 \mathrm{H}^{+} \longrightarrow \gamma-\mathrm{Fe}_{2} \mathrm{O}_{3} \text { (maghemite }\right)+\mathrm{Fe}^{2+}+\mathrm{H}_{2} \mathrm{O},
$$

followed by its conversion to stable goethite or hematite (at low $a \mathrm{H}_{2} \mathrm{O}(\mathrm{l})$ and in anhydrous conditions in the equatorial region). A paucity of magnetite in primary rocks (as in several Martian meteorites) makes formation of secondary $\mathrm{Fe}^{3+}$ phases entirely dependent on oxidation that becomes efficient only at elevated $\mathrm{pH}$ and $P_{\mathrm{O}_{2}}$.

[44] Our results demonstrate that Martian acid weathering supplies $\mathrm{Fe}^{2+}$ in solution faster than it oxidizes by dissolved $\mathrm{O}_{2}$. This may cause precipitation of ferrous phyllosilicates (smectites and chlorites), as well as deposition of ferrous sulfates and chlorides during freezing and/or evaporation. If solution does not freeze or evaporate in $\mathrm{O}_{2}$-deficient conditions $\left(P_{\mathrm{O}_{2}}<\sim 10^{-4}\right.$ bar), formation of ferrous phyllosilicates consumes $\mathrm{Fe}^{2+}$ from solution, delays its neutralization, decreases $\mathrm{Fe}^{2+}$ oxidation rate, and leads to smaller amounts of goethite compared to acid weathering at $\mathrm{O}_{2}$-rich Earthlike conditions (Figures 9 and 10). A rapid supply of $\mathrm{Fe}^{2+}$ in solution during weathering of fine particles at low $W / R$ ratios can cause deposition of daphnite and siderite (Figures 4-7). Overall, our models demonstrate that shorttime episodes of acid weathering on Mars should not cause significant oxidation, especially at current $P_{\mathrm{O}_{2}}$.

[45] In addition to short duration of $\mathrm{O}_{2}$-rich periods, oxidation could be limited by $\mathrm{Fe}^{3+}$-oxide coatings that restrict dissolution of primary and secondary ferrosilicates, as it happens on Earth. An early deposition of silica and $\mathrm{Fe}^{3+}$ hydroxide during freezing/evaporation of acid solutions would also lead to protective coatings. It is possible that ferric oxide (and silica?) coatings on magnetite dust particles [Goetz et al., 2005] prevented thorough oxidation of the mineral.

[46] A prolonged single acid weathering episode on Mars could have led to deposition of mostly ferrous phases: sulfates, chlorides, smectites, chlorites, and siderite, while formation of goethite was mainly related to dissolution of magnetite. Subsequent weathering events would first cause dissolution of ferrous salts and make $\mathrm{Fe}^{2+}$ available for oxidation. Dissolution of ferrous phyllosilicates, and primary minerals would supply $\mathrm{Fe}^{2+}$ ions as well. It follows that irreversible $\mathrm{Fe}^{2+}$ oxidation could have occurred through multiple aqueous events in the presence of $\mathrm{O}_{2}$ in the atmosphere $\left(P_{\mathrm{O}_{2}}>\sim 10^{-7}\right.$ bar). Aqueous decomposition of $\mathrm{H}_{2} \mathrm{O}_{2}$, which could be present in the soil [e.g., Yen et al., 2000], provided an additional $\mathrm{O}_{2}$ source. Oxidation of $\mathrm{Fe}^{2+}$-saponite could have led to formation of nontronite that is tentatively detected in small surface regions [Poulet et al., 2005] and layered rocks at Meridiani Planum [Glotch et al., 2006]. Although oxidation of $\mathrm{Fe}^{2+}$-saponite to poorly crystalline nontronite occurs on Earth [Kohyama and Sudo, 
1975], efficiency of Martian oxidation of saponite is limited by low $P_{\mathrm{O}_{2}}$ and a necessity of advanced $\mathrm{Mg}$ leaching from octahedral sites.

[47] Formation of significant amounts of $\mathrm{Fe}^{3+}$ compounds, as in hematite-rich regions [Christensen et al., 2001b], requires the involvement of significant masses of $\mathrm{O}_{2}$, which are comparable with the atmospheric abundance. These masses of $\mathrm{O}_{2}$ may not be related to periods of active volcanism [Catling and Moore, 2003] but could have been produced in large impacts (see section 4.5).

\subsection{Dust Weathering, Weathering Rinds, and Specifics of Northern Lowlands}

[48] Martian dust contains an abundant semicrystalline silicate component, as seen in the near-infrared [Soderblom, 1992; Murchie et al., 2000; Bibring et al., 2005] and thermal infrared [Michalski et al., 2006a] spectra of highalbedo surface regions. The dust is not rich in primary minerals (except magnetite, and, probably, plagioclase) but sulfates and chlorides are likely to be abundant. The altered semicrystalline nature of Martian dust ( $<10$ micron) agrees with rapid acid weathering of small particles (Figures 4 and 5b). Although solution could be neutralized within a year in a closed system, subsequent acid attacks may destroy secondary phases, leading to semicrystalline silicates and $\mathrm{Si}$-, $\mathrm{Al}-, \mathrm{Fe}^{3+}$-oxides. Inefficient low-temperature crystallization of phyllosilicates is observed on Earth and suggested for Mars [e.g., Michalski et al., 2006b]. High concentrations of $\mathrm{S}$ and $\mathrm{Cl}$ in Martian fines could reflect an incorporation of these elements during multiple acid attacks.

[49] Dust particles weather in acid atmospheric aerosols, as a soil component, as well as on surfaces of rocks. In the latter case, weathering would produce a layer of alteration products that contain elements that came from the dust and the rock. Surface layers enriched in $\mathrm{Fe}^{3+}, \mathrm{S}, \mathrm{Cl}$, and $\mathrm{Br}$ on basaltic rocks in Gusev crater may reveal their complex formation [Haskin et al., 2005; Gellert et al., 2006; McSween et al., 2004, 2006; Hurowitz et al., 2006]. As for dust alteration, multiple acid attacks on surface rocks could have prevented formation and accumulation of minerals formed from neutralized solutions. In addition, minerals could be affected by lowering $\mathrm{pH}$ during freezing and/ or evaporation of solutions (Figures 11 and 12). As a result, silica, $\mathrm{Mg}$-, $\mathrm{Fe}^{2+}$-, and $\mathrm{Ca}$-sulfates and chlorides, amorphous Al-bearing mineraloids (Al-bearing opal [Michalski et al., 2005]), and ferric oxides and sulfates (not modeled here) could compose weathered products on surfaces of basaltic rocks at the end of each weathering episode. The observations of chemically distinct rock surfaces of olivine basalts on plains in Gusev crater [Haskin et al., 2005] agrees with this view. In particular, the lack of evidence for carbonates, smectites, and zeolites on rock surfaces and soils reveals short-term and/or multiple acid attacks.

[50] Abundant $\mathrm{Mg}$ sulfates in Martian surface materials are consistent with freezing and/or evaporation of low-pH $(<7.5)$ fluids formed through acid weathering of basaltic materials. This notion agrees with inferences in recent works [e.g., Tosca et al., 2005; Clark et al., 2005; Hurowitz et al., 2006]. Despite some differences in mineralogy of freezing and evaporation of acid solutions, Martian soil mineralogy may not reveal the leading process of salt precipitation. Although evaporation results in less hydrated solids than freezing, many salts may then dehydrate to equilibrate with atmospheric $\mathrm{H}_{2} \mathrm{O}$, especially at low latitudes. At present $T-P_{\mathrm{H} 2 \mathrm{O}}$ conditions in the equatorial belt, ice is not stable near the surface, and precipitated salts could dehydrate to $\mathrm{MgSO}_{4} \cdot \mathrm{H}_{2} \mathrm{O}, \mathrm{FeSO}_{4} \cdot \mathrm{H}_{2} \mathrm{O}, \mathrm{FeCl}_{2} \cdot 2 \mathrm{H}_{2} \mathrm{O}$, $\mathrm{MgCl}_{2} \cdot 2 \mathrm{H}_{2} \mathrm{O}, \mathrm{CaSO}_{4}$, and $\mathrm{NaCl}$ [Zolotov, 1989].

[51] Northern low-albedo regions with strong spectral features of "silica-rich phases" and weak pyroxene signal [e.g., Bandfield et al., 2000; Mustard et al., 2005] could have been affected by more intense, and/or longer acid weathering, as well as lower $\mathrm{pH}$ solutions compared to equatorial and southern regions, which do not reveal these features. The spectral observations may reflect lower altitude, higher atmospheric pressure, higher atmospheric humidity [Jakosky and Farmer, 1982], larger amounts of ground ice, and more importantly accumulation of surface ice during periods on high obliquity compared to equatorial and southern highlands. All these conditions may cause slower evaporation/freezing, higher $W / R$ ratios, and longer contacts of solution with rocks and soils in northern lowlands.

[52] During periods of high obliquity, acid rock weathering could have occurred through accumulation of acid aerosols and raindrops (see section 4.5) on ice followed by the migration of acid brine pockets toward the iceregolith boundary. An isolation of acid brine pockets from the atmosphere prevented their evaporation. The low temperature of the $\mathrm{H}_{2} \mathrm{SO}_{4}-\mathrm{H}_{2} \mathrm{O}$ and $\mathrm{HCl}-\mathrm{H}_{2} \mathrm{O}$ eutectics $\left(-62^{\circ} \mathrm{C}\right.$ and $\sim-87^{\circ} \mathrm{C}$, respectively) and low water activities $(\sim 0.8-0.5)$ of low-temperature acid brines allow temporal solution existence near ice even at present climate. During winters, acid brines pockets could have frozen to form $\mathrm{H}_{2} \mathrm{SO}_{4}$ hydrate (see Figure 11). Melting at warmer seasons favored brine migration toward rocks. Accumulated subglacial aqueous solutions could have led to a prolonged acid alteration of rocks compared to rapidly evaporating (and/or freezing) acid precipitates on ice-free surfaces.

[53] Thermal insulation by thick ice layers could have caused an increase in temperature in lower horizons and also favored downward migration of acid brines and their accumulation at the ice-regolith interface. In addition, this process could have been enhanced by melting at ice-regolith boundaries at low altitudes [Richardson and Mischna, 2005]. This mechanism would cause acid weathering of uppermost regolith layers and is consistent with signs of aqueous migration of silica, and $\mathrm{Mg}$, and $\mathrm{Fe}^{3+}$ species observed in rock coatings and excavated soils in Gusev crater [Haskin et al., 2005; Wang et al., 2006b]. Note that melting at the ice-surface interface has been proposed to account for those observations [Arvidson et al., 2004; Haskin et al., 2005].

\subsection{Acid Weathering in Martian History: Role of Impacts and Volcanism}

[54] Volcanic eruptions and impacts could have been responsible for multiple short-term episodes of acid weathering as a dry and cold climate prevailed over history. The effect of volcanism on generation of acid solutions is mostly attributed to degassing of $\mathrm{SO}_{2}, \mathrm{H}_{2} \mathrm{~S}$, and $\mathrm{HCl}$. However, a consumption of photochemically produced atmospheric oxidants $\mathrm{O}_{2}, \mathrm{O}_{3}, \mathrm{OH}$, and peroxides [Yung and DeMore, $1999])$ in reactions with reduced volcanic gases $\left(\mathrm{H}_{2} \mathrm{~S}, \mathrm{CO}\right.$, 
$\mathrm{H}_{2}$, and $\mathrm{S}_{2}$ [Zolotov, 2003]) would limit the generation of sulfuric acid through oxidation of $\mathrm{SO}_{2}$ and $\mathrm{H}_{2} \mathrm{~S}$. Without photosynthesis, active volcanic degassing could have limited amounts of strong atmospheric oxidants on early Earth [Holland, 1984] and Mars [Catling and Moore, 2003]. Without oxidants, only moderately acid solutions could form because of a limited abundance of volcanic $\mathrm{HCl}$ and HF [Symonds et al., 1994; Zolotov, 2003], a mild dissociation of $\mathrm{H}_{2} \mathrm{~S}$ in solutions $\left(\mathrm{H}_{2} \mathrm{~S} \rightarrow \mathrm{H}^{+}+\mathrm{HS}^{-}\right)$, and a low solubility of $\mathrm{SO}_{2}$ compared to $\mathrm{SO}_{3}$, which forms sulfuric acid. Acid generation through formation of pyrite from dissolved $\mathrm{H}_{2} \mathrm{~S}\left(2 \mathrm{H}_{2} \mathrm{~S}+\mathrm{Fe}^{2+} \rightarrow 2 \mathrm{H}^{+}+\mathrm{H}_{2}+\mathrm{FeS}_{2}\right)$ could have been limited by the supply of $\mathrm{Fe}^{2+}$ through dissolution of ferrous silicates. Likewise, formation of low-pH fluids would have been limited in the anoxic Martian subsurface. An alkaline nature of Martian subsurface solutions [Zolotov et al., 2004], high concentrations of cations in brines, and low $W / R$ ratios would have favored rapid neutralization of volcanic acid gases and fluids. Involvement of photochemical $\mathrm{O}_{2}$ into oxidation of $\mathrm{SO}_{2}$ [Settle, 1979] and $\mathrm{H}_{2} \mathrm{~S}$, as well as $\mathrm{Fe}$ sulfides, provided a major contribution into generation of sulfuric acid, but makes acid weathering a near-surface phenomenon that may not be closely related to volcanism. Finally, volcanic eruptions could not have led to acid raining owing to cold and dry climate throughout history [Haberle, 1998].

[55] Although volcanism was likely to be responsible for the net supply of $\mathrm{S}$ and halogens to the Martian surface [e.g., Clark and Baird, 1979; Clark and Van Hart, 1981], the effects of large impacts on aqueous acid weathering and erosion could have been greater than the effects of volcanism. On Earth, the role of impacts in generating acid aerosols and rains has been realized in the context of Chicxulub crater at the Cretaceous-Tertiary boundary [Ivanov et al., 1996; Pope et al., 1997; Pierazzo et al., 1998]. These studies show that the Chicxulub impact into sulfate-bearing sediments released several orders of magnitude more sulfur gases compared to a volcanic eruption. On Mars, the elevated abundance of sulfates in the regolith implies similar effects. Impact generation of $\mathrm{SO}_{2}$ and/or $\mathrm{SO}_{3}$ through decomposition of sulfates [Lyons and Ahrens, 1996; Ivanov et al., 1996; Gupta et al., 2001], as well as other oxidized gases $\left(\mathrm{O}_{2}, \mathrm{O}_{3}, \mathrm{NO}, \mathrm{NO}_{2}\right.$ [e.g., Prinn and Fegley, 1987; Gerasimov, 2002; Gerasimov et al., 2002]) provided reactants to form acids in cooling impact plumes and clouds. Oxidation of sulfides in target and projectile contributed to the release of S-bearing gases. Note that mass independent fractionation of $\mathrm{S}$ isotopes observed in Martian meteorites [Farquhar et al., 2000] does not exclude impact degassing and recycling of sulfur through the atmosphere. On the surface, aqueous interaction of strong oxidants with $\mathrm{Fe}^{2+}$ and sulfides caused oxidation of $\mathrm{S}$ and $\mathrm{Fe}$ and produced $\mathrm{H}^{+}$. In addition, atmospheric oxidants, which would not be abundant during periods of volcanic activity, would react with impact-generated $\mathrm{H}_{2} \mathrm{~S}, \mathrm{SO}_{2}$, and $\mathrm{NO}$ to form $\mathrm{SO}_{3}$ and $\mathrm{NO}_{2}$, as well as oxidize $\mathrm{Fe}^{2+}$ in surface solutions. In $\mathrm{H}_{2} \mathrm{O}-$ bearing impact environments, hydrogen halides could form through decomposition of soil halides and igneous chlorapatite, which is abundant in Martian meteorites.

[56] Dissolution of $\mathrm{SO}_{3}, \mathrm{H}_{2} \mathrm{~S}, \mathrm{NO}, \mathrm{NO}_{2}$, and $\mathrm{HCl}$ in water droplets formed through condensation in an impact cloud would have led to an array of acids. Although sulfuric and hydrochloric acids were probably most abundant, cometary impacts could have led to nitrous and nitric acids [Prinn and Fegley, 1987]. Local and global raining from impact clouds, which is expected in the present climate [Segura et al., 2002], generated acid solutions on the surface. Plentiful impact-generated fine-grained material and silicate glasses would be primarily altered by acid rains/aerosols, consistent with an altered nature of Martian dust and air-blown particles. Acid rainfalls also affected upper surface layers and locally penetrated to deeper horizons upon accumulation in surface depressions. Freezing and/or evaporation of acid solutions led to deposition of sulfates and chlorides. We suggest that sulfate-bearing rocks and soils were a cumulative effect of multiple-impact produced acid volatiles, at least initially from volcanic emissions and impacts on sulfide-rich rocks [cf. Burt et al., 2006].

[57] Penetration of impact-generated acid fluids into surface ice sheets restricted their evaporation and prevented freezing until temperatures of acid-rich eutectics (see Table 3 and Figure 11). During periods of elevated obliquity, subglacial acid weathering by these fluids could have been responsible for the formation of silica-bearing and pyroxenedepleted surfaces in Northern lowlands (e.g., TES surfacetype 2 in Acidalia Planitia [Wyatt and McSween, 2002]) and also in middle altitudes in the Southern hemisphere. In addition, these processes could have played a role in the equatorial latitudes, where surface ice could temporary exist at high obliquities.

[58] Impact-generated acid rains could have been responsible for the vertical migration of $\mathrm{Si}$ and $\mathrm{Fe}^{3+}$ suggested for excavated soils in Gusev crater [Haskin et al., 2005; Wang et al., 2006b]. The elevated abundance of $\mathrm{Si}$ and $\mathrm{Fe}^{3+}$ observed at depth of $\sim 10 \mathrm{~cm}$ [Wang et al., 2006b] may reflect dissolution of surface minerals in low-pH solutions followed by precipitation of silica and $\mathrm{Fe}^{3+}$ hydroxide in the shallow subsurface. Acid precipitating from impact plumes may also account for the high abundance of amorphous or semicrystalline material and lack of detection of crystalline phyllosilicates, carbonates, and zeolites in heavily altered rocks at Columbia Hills [Ruff et al., 2006]. This reveals a low-temperature acidic alteration occurred over a limited timescale. The diverse and patchy nature of aqueous processes in Columbia Hills [Ming et al., 2006] could be related to mixing from impact event(s), implying transient involvement of aqueous solutions.

[59] An interaction of heavily altered salt-rich deposits (as in Meridiani Planum [Clark et al., 2005]) with acid rainwater could have not led to rapid neutralization, but increased the amount of salts in deposits. Impact-generated acid rainfalls over proposed impact surge deposits at Meridiani Planum [Knauth et al., 2005] do not contradict with observations and arguments for acidic aqueous conditions [Clark et al., 2005; McLennan et al., 2005] and agree with an addition of $\mathrm{S}$ and $\mathrm{Cl}$ to basaltic material [McCollom and Hynek, 2005]. A formation of abundant ferric iron phases in layered bedrocks [Klingelhöfer et al., 2004; Glotch et al., 2006] could have been driven by plentiful impact-generated oxidants. A possibility exists that the deposition of impact surge deposits and low-pH aqueous processes were related to a large single impact in Meridiani Planum.

[60] In addition to our earlier suggestions, a large degree of rock alteration and/or elevated silica content in northern 
low-albedo regions [Wyatt and McSween, 2002; Kraft et al., 2003; Michalski et al., 2005] could be related to impact degassing of more abundant ground ice, sulfate, and other hydrated salt deposits as compared to equatorial and southern highlands. Finally, a correlation of $\mathrm{P}$ with $\mathrm{S}$ and $\mathrm{Cl}$ observed in MER sites could be explained by multiple acid rainfalls that delivered $\mathrm{S}$ and $\mathrm{Cl}$ and favored $\mathrm{P}$ mobility [Greenwood and Blake, 2006].

[61] A high impact rate in Noachian implies an efficient acid weathering followed by surface erosion, aqueous transport, and deposition of salts and suspended particles in temporal water reservoirs. In fact, Segura et al. [2002] show that impact-generated rainfalls could have been responsible for the high erosion rate in Noachian time [cf. Craddock and Howard, 2002] and the formation of valley networks. No warm and wet climate is needed for impactinduced exogenic processes. It follows that a majority of aqueous oxidation, formation of silica, and $\mathrm{Mg}-\mathrm{Fe}-\mathrm{Ca}$ sulfates could have occurred in the earliest period of geological history.

[62] With or without a warm and wet climate, frequent large impacts in Early Noachian caused stronger rainfalls and longer duration of weathering episodes compared to subsequent epochs. Warm/wet climate would have reduced the impact of acid weathering because of dilution of acids in persistent and neutralized surface water reservoirs. The longer duration of weathering episodes favored partial and/or local neutralization in temporal surface water reservoirs. A presence of tentatively detected nontronite in Meridiani Planum [Glotch et al., 2006] may reflect neutralization that facilitated the growth of $\mathrm{Fe}^{3+}$ oxide concretions [Zolotov and Shock, 2005]. The neutralization could have been slowed because of accumulation of $\mathrm{H}^{+}$through freezing/evaporation (Figures 11 and 12), a conversion of jarosite to goethite, the absence of rapidly dissolving pyroxenes and olivine, and possible silica/ $\mathrm{Fe}^{3+}$-oxide coatings. At Columbia Hills, an existence of poorly crystalline [Ruff et al., 2006] kaolinite-type aluminosilicates in some Clovis class rocks indicates mildly acidic conditions [Wang et al., 2006a] ( $\mathrm{pH}>\sim 3.5$, see Figure 2), which may imply some neutralization of original acid solutions.

[63] In other locations, more advanced neutralization could have occurred. An evaporitic formation of carbonates in the ALH85001 Martian meteorite [Warren, 1998] about 3.9-4.0 Ga ago implies nonacidic $\mathrm{pH}$, which may also reflect neutralization at some depth. The only local occurrence of smectite deposits [Poulet et al., 2005] in Noachianage regions indicates spatially limited neutralization. Using terrestrial analogues, the formation of observed layered clay deposits could have occurred through surface weathering followed by aqueous transport in suspension and accumulation in water reservoirs. A massive nature of Noachian clay deposits and low permeability could have limited their weathering by subsequent acid attacks. To conclude, acid weathering in Noachian probably played a larger role compared to subsequent epochs, though achieved larger degrees of neutralization because of longer existence of surface solutions and their temporal accumulation in surface reservoirs, where clays deposited. Although the intensity of impact-induced acid weathering declined in time, low-pH aqueous processes could have also been important during the Hesperian epoch, when volcanism reached its highest levels in history [Tanaka et al., 1992] and large impacts still occurred.

\section{Summary}

[64] 1. Kinetic-thermodynamic modeling of acid weathering of olivine basalt in a closed system reveals a timedependent sequence of mineral precipitation and evolution of solution composition. Results demonstrate preferential dissolution of olivine and pyroxenes at low $\mathrm{pH}$ followed by predominant dissolution of plagioclase at higher $\mathrm{pH}$. Solution evolves from acidic $\mathrm{Mg}$-Fe-rich compositions toward Na-rich alkaline fluids. Early low-pH stages of weathering are characterized by the formation of amorphous silica and ferric hydroxides/oxyhydroxides formed through dissolution of magnetite. Formation of smectites, carbonates, and zeolites requires major neutralization and takes significantly more time than the deposition of silica. Inefficient $\mathrm{Fe}^{2+}$ oxidation under low-pH and $\mathrm{O}_{2}$-deficient conditions causes precipitation of secondary ferrous phases. Neutralization and mineral precipitation occur faster at higher solution $\mathrm{pH}$, lower $W / R$ ratios, and larger surface areas of exposed materials. Although short episodes of acid weathering cannot lead to significant alteration of rocks, dust-size particles could be altered within hours.

[65] 2. The comparison of models with Martian surface data reveals multiple episodes of acid sulfate weathering that rarely led to neutralization of solution and ceased because of freezing and/or evaporation. This notion is supported by (1) the likely presence of amorphous silica, $\mathrm{Fe}^{3+}$-secondary phases, semicrystalline silicates, and abundant Mg sulfates in surface materials, (2) faint spectral features of pyroxene in northern low-albedo regions, dust, and MER sites, (3) the occurrence of primary minerals in soil and dust, and (4) a lack of widespread and abundant smectites, zeolites, and carbonates.

[66] 3. Freezing of Martian $\mathrm{H}_{2} \mathrm{SO}_{4}-\mathrm{HCl}$ acid solutions could have caused the deposition of abundant $\mathrm{Mg}$ sulfates and $\mathrm{Fe}^{2+}$ salts, a decrease in $\mathrm{pH}$, and the formation of sulfuric acid hydrate at low-temperature eutectics $\left(\sim 60^{\circ} \mathrm{C}\right)$. If isolated from the atmosphere (e.g., in ice), acid eutectic solutions could exist at the average surface temperature of present Mars and may contribute into acid weathering of subglacial materials.

[67] 4. Generation of $\mathrm{O}_{2}$ and other oxidants, decomposition of sulfates, and oxidation of sulfides through strong impacts could have provided a major source of sulfuric acid throughout Martian history. The formation of impactgenerated acid rains and aerosols may account for signs of acid weathering in Gusev crater, Meridiani Planum, the Mars Pathfinder landing site, as well as for silica-rich phases and a pyroxene deficiency observed in northern low-albedo regions. The formation of strong oxidants by impacts could have mainly contributed to aqueous oxidation of $\mathrm{Fe}^{2+}$ that was inefficient during periods of volcanism. Despite slow oxidation at low $\mathrm{pH}$, large impacts led to incremental oxidation of $\mathrm{Fe}^{2+}$ released from primary minerals and previously formed secondary ferrous phases. Volcanic generation of acids could have been important during Hesperian time but limited by the photochemical production of atmospheric oxidants. 
[68] 5. Although impact-generated acid rainfalls could have caused intense weathering and erosion in Noachian time, dilution of acids and a prolonged existence of surface aqueous solutions favored local neutralization of solution, and formation, aqueous transport and deposition of clay minerals in water reservoirs.

\section{Notation}

$a$ activity of a solute.

$\Delta G$ Gibbs free energy of reaction, $\mathrm{J} \mathrm{mol}^{-1}$.

$E a$ apparent activation energy, $\mathrm{J} \mathrm{mol}^{-1}$.

$F_{S_{i}}$ fraction of mineral surface exposed to solution.

$K_{0 H^{+}}$rate constant for dissolution at $\mathrm{pH}$ below $\mathrm{pH}$ of zero charged surface at $298.15 \mathrm{~K}$.

$K_{0 H 2 O}$ rate constant for dissolution at $\mathrm{pH}$ of zero charged surface at $298.15 \mathrm{~K}$.

$\mathrm{K}_{0 \mathrm{OH}-}$ rate constant for dissolution at $\mathrm{pH}$ above $\mathrm{pH}$ of zero charged surface at $298.15 \mathrm{~K}$.

$K_{w}$ ionic product of water.

$P_{j} \quad$ partial pressure of gas, bar.

$R$ gas constant, $\mathrm{J} \mathrm{mol} \mathrm{K}^{-1}$.

$r_{i}$ rate of mineral dissolution, $\mathrm{mol} \mathrm{m}^{-2} \mathrm{~s}^{-1}$.

$R_{i} \quad$ radius of spherical mineral grains, $\mathrm{m}$.

$S_{i}$ mineral surface area exposed to aqueous solution, $\mathrm{m}^{2}$.

$T$ absolute temperature, $\mathrm{K}$.

$T_{0}$ standard temperature $(298.15 \mathrm{~K})$.

$V_{i}$ volume of mineral grains, $\mathrm{m}^{3}$.

$W / R$ water to rock mass ratio.

$x_{i}$ molar amount of mineral $(i)$ dissolved at each time step.

$\Delta t$ duration of current time step, s.

[69] Acknowledgments. We thank Venyamin B. Polyakov for helpful discussions and advice and Viktor A. Alekseev for sharing preprints on kinetics of mineral dissolution. We also appreciate Amy McAdam for reviewing some data on mineral dissolution. This work benefited from discussions with Amy McAdam, Christopher Glein, and Everett Shock and comments from them. We thank Giles Marion for the constructive review. This research is supported by NASA Mars Fundamental Research program grant NNG06GH14G, NASA Exobiology and Evolutionary Biology program grant NNG05GQ67G, and NSF Planetary Astronomy grant AST0507778.

\section{References}

Aagaard, P., and H. C. Helgeson (1982), Thermodynamic and kinetic constraints on reaction rates among minerals and aqueous solutions: I. Theoretical considerations, Am. J. Sci., 282, 237-285.

Alekseev, V. A. (2005), Kinetics of reactions of rock-forming minerals with aqueous solutions (in Russian), in Geological Evolution and SelfOrganization of the Water-Rock System, vol. 1, edited by S. L. Shvartsev, pp. 71-107, Publ. House of the Siberian Branch of Russ. Acad. of Sci., Novosibirsk.

Alekseev, V. A. (2007), Equations of rates of dissolution of montmorillonite, illite, and chlorite, Geochem. Int, in press.

Amram, K., and J. Ganor (2005), The combined effect of $\mathrm{pH}$ and temperature on smectite dissolution rate under acidic conditions, Geochim. Cosmochim. Acta, 69, 2535-2546.

Arvidson, R. E., et al. (2004), Localization and physical properties experiments conducted by Spirit at Gusev crater, Science, 305, 821-824.

Bandfield, J. L. (2002), Global mineral distributions on Mars, J. Geophys. Res., 107(E6), 5042, doi:10.1029/2001JE001510.

Bandfield, J. L., and M. D. Smith (2003), Multiple emission angle surfaceatmosphere separations of Thermal Emission Spectrometer data, Icarus, 161, 47-65.

Bandfield, J. L., V. E. Hamilton, and P. R. Christensen (2000), A global view of Martian surface compositions from MGS-TES, Science, 287, $1626-1630$.
Banin, A., B. C. Clark, and H. Wänke (1992), Surface chemistry and mineralogy, in Mars, edited by H. H. Kieffer et al., pp. 594-625, Univ. of Ariz. Press, Tucson.

Banin, A., F. X. Han, I. Kan, and A. Cicelsky (1997), Acidic volatiles and the Mars soil, J. Geophys. Res., 102, 13,341-13,365.

Bauer, A., and G. Berger (1998), Kaolinite and smectite dissolution rate in high molar $\mathrm{KOH}$ solutions at $35^{\circ}$ and $80^{\circ} \mathrm{C}$, Appl. Geochem., 13, $905-$ 916.

Bell, J. F., et al. (2000), Mineralogic and compositional properties of Martian soil and dust: Results from Mars Pathfinder, J. Geophys. Res., 105, $1721-1755$.

Bethke, G. M. (1996), Geochemical Reaction Modeling: Concepts and Applications, 397 pp., Oxford Univ. Press, New York.

Bibring, J.-P., et al. (2005), Mars surface diversity as revealed by the OMEGA/Mars Express observations, Science, 307, 1576-1581.

Bibring, J.-P., et al. (2006), Global mineralogical and aqueous Mars history derived from OMEGA/Mars Express data, Science, 312, 400-404.

Blum, A. E., and L. L. Stillings (1995), Feldspar dissolution kinetics, in Chemical Weathering Rates of Silicate Minerals, Rev. Mineral., vol. 31, edited by A. F. White and S. L. Brantley, pp. 291-351, Mineral. Soc. of Am., Washington, D. C

Brady, P. V., and J. V. Walther (1989), Controls on silicate dissolution rates in neutral and basic $\mathrm{pH}$ solutions at $25^{\circ} \mathrm{C}$, Geochim. Cosmochim. Acta, $53,2823-2830$.

Brady, P. V., and J. V. Walther (1990), Kinetics of quartz dissolution at low temperatures, Chem. Geol., 82, 253-264.

Brantley, S. L. (2004), Reaction kinetics of primary rock-forming minerals under ambient conditions, in Treatise on Geochemistry, vol. 5, Surface and Ground Water, Weathering, and Soils, edited by J. I. Drever, pp. $73-$ 118, Pergamon, Oxford, U. K.

Bridges, J. C., et al. (2001), Alteration assemblages in Martian meteorites: Implications for near-surface processes, Space Sci. Rev., 96, 365-392.

Burns, R. G. (1993), Rates and mechanisms of chemical weathering of ferromagnesian silicate minerals on Mars, Geochim. Cosmochim. Acta, $57,4555-4574$

Burns, R. G., and D. S. Fisher (1990), Iron-sulfur mineralogy of Mars: Magmatic evolution and chemical weathering products, J. Geophys. Res., 95, 14,169-14,173.

Burt, D. M., K. H. Wohletz, and L. P. Knauth (2006), Mars and mine dumps, Eos Trans. $A G U, 87(49), 549-552$.

Cama, J., J. Ganor, C. Ayora, and C. A. Lasaga (2000), Smectite dissolution kinetics at $80^{\circ} \mathrm{C}$ and $\mathrm{pH} 8.8$, Geochim. Cosmochim. Acta, 64, $2701-$ 2717.

Cama, J., V. Metz, and J. Ganor (2002), The effect of $\mathrm{pH}$ and temperature on kaolinite dissolution rate under acidic conditions, Geochim. Cosmochim. Acta, 66, 3913-3926.

Carr, M. H. (1996), Water on Mars, 229 pp., Oxford Univ. Press, New York.

Carrol, S. A., and J. V. Walther (1990), Kaolinite dissolution at $25^{\circ}, 60^{\circ}$, and $80^{\circ} \mathrm{C}, \mathrm{Am} . \mathrm{J}$. Sci., 290, 797-810.

Catling, D. C., and J. Moore (2003), The nature of course-grained crystalline hematite and its implications for early environment of Mars, Icarus, $165,277-300$.

Chen, Y., and S. L. Brantley (2000), Dissolution of forsteritic olivine at $65^{\circ} \mathrm{C}$ and $2<\mathrm{pH}<5$, Chem. Geol., 165, 267-281.

Christensen, P. R., et al. (2001a), Mars Global Surveyor Thermal Emission Spectrometer experiment: Investigation description and surface science results, J. Geophys. Res., 106, 23,823-23,872.

Christensen, P. R., R. V. Morris, M. D. Lane, J. L. Bandfield, and M. C. Malin (2001b), Global mapping of Martian hematite mineral deposits: Remnants of water-driven processes on early Mars, J. Geophys. Res., $106,23,873-23,886$.

Clark, B. C., and A. K. Baird (1979), Is the Martian lithosphere sulfur rich?, J. Geophys. Res., 84, 8395-8403.

Clark, B. C., and D. C. Van Hart (1981), The salts of Mars, Icarus, 45, $370-378$.

Clark, B. C., A. K. Baird, R. J. Weldon, D. M. Tsusaki, L. Schabel, and M. P. Candelaria (1982), Chemical composition of Martian fines, J. Geophys. Res., 87, 10,059-10,067.

Clark, B. C., et al. (2005), Chemistry and mineralogy of outcrops at Meridiani Planum, Earth Planet. Sci. Lett., 240, 73-94.

Craddock, R. A., and A. D. Howard (2002), The case for rainfall on a warm, wet early Mars, J. Geophys. Res., 107(E11), 5111, doi:10.1029/ 2001JE001505.

Dove, P. M. (1995), Kinetic and thermodynamic controls on silica reactivity in weathering environments, in Chemical Weathering Rates of Silicate Minerals, Rev. Mineral., vol. 31, edited by A. F. White and S. L. Brantley, pp. 235-290, Mineral. Soc. of Am., Washington. D. C.

Dove, P. M., and J. D. Rimstidt (1994), Silica-water interactions, in Silica: Physical Behavior, Geochemistry and Materials Applications, Rev. 
Mineral., vol. 29, edited by P. J. Heaney, C. T. Prewitt, and G. V. Gibbs, pp. 259-308, Mineral. Soc. of Am., Washington, D. C.

Farquhar, J., J. Savarino, T. L. Jackson, and M. H. Thiemens (2000), Evidence of atmospheric sulphur in the Martian regolith from sulphur isotopes in meteorites, Nature, 404, 50-52.

Fergason, R. L., P. R. Christensen, J. F. Bell III, M. P. Golombek, K. E. Herkenhoff, and H. H. Kieffer (2006), Physical properties of the Mars Exploration Rover landing sites as inferred from Mini-TES-derived thermal inertia, J. Geophys. Res., 111, E02S21, doi:10.1029/ 2005JE002583.

Fernández-Remolar, D. C., et al. (2004), The Tinto River, an extreme acidic environment under control of iron, as an analog of the Terra Meridiani hematite site of Mars, Planet. Space Sci., 52, 239-248.

Fernández-Remolar, D. C., et al. (2005), The Río Tinto Basin, Spain: Mineralogy, sedimentary geobiology, and implications for interpretation of outcrop rocks at Meridiani Planum, Mars, Earth Planet. Sci. Lett., 240, $149-167$

Foley, C., T. Economou, and R. Clayton (2003), Final chemical results from the Mars Pathfinder alpha proton X-ray spectrometer, J. Geophys. Res., 108(E12), 8096, doi:10.1029/2002JE002019.

Fridriksson, T., P. S. Neuhoff, S. Arnorsson, and D. K. Bird (2001), Geological constraints on the thermodynamic properties of the stilbite-stellerite solid solution in low-grade metabasalts, Geochim. Cosmochim. Acta, 65, $3993-4008$

Ganor, J., J. L. Mogollón, and A. C. Lasaga (1995), The effect of pH on kaolinite dissolution rates and on activation energy, Geochim. Cosmochim. Acta, 59, 1037-1052.

Gellert, R., et al. (2006), Alpha Particle X-Ray Spectrometer (APXS): Results from Gusev crater and calibration report, J. Geophys. Res., 111, E02S05, doi:10.1029/2005JE002555.

Gendrin, A., et al. (2005), Sulfates in Martian layered terrains: The OMEGA/Mars Express view, Science, 307, 1587-1591.

Gerasimov, M. V. (2002), Toxins produced by meteorite impacts and their possible role in a biotic mass extinction, Spec. Pap. Geol. Soc. Am., 356 , $705-716$.

Gerasimov, M. V., Y. P. Dikov, O. I. Yakovlev, and F. Wlotzka (2002), Experimental investigation of the role of water in impact evaporation chemistry, Deep Sea Res., Part II, 49(6), 995-1009.

Glotch, T. D., J. L. Bandfield, P. R. Christensen, W. M. Calvin, S. M. McLennan, B. C. Clark, A. D. Rogers, and S. W. Squyres (2006), Mineralogy of the light-toned outcrop at Meridiani Planum as seen by the Miniature Thermal Emission Spectrometer and implications for its formation, J. Geophys. Res., 111, E12S03, doi:10.1029/2005JE002672.

Goetz, W., et al. (2005), Indication of drier periods on Mars from the chemistry and mineralogy of atmospheric dust, Nature, 436, 62-65.

Golden, D. C., R. V. Morris, D. W. Ming, H. V. Lauer Jr., and S. R. Yang (1993), Mineralogy of three slightly palagonitized basaltic tephra samples from the summit of Mauna Kea, Hawaii, J. Geophys. Res., 98, 34013411

Golden, D. C., D. W. Ming, R. V. Morris, and S. A. Mertzman (2005), Laboratory-simulated acid-sulfate weathering of basaltic materials Implications for formation of sulfates at Meridiani Planum and Gusev crater, Mars, J. Geophys. Res., 110, E12S07, doi:10.1029/2005JE002451.

Greeley, R., R. Leach, B. White, J. Iversen, and J. Pollack (1980), Threshold windspeeds for sand on Mars: Wind tunnel simulations, Geophys. Res. Lett., 7, 121-124.

Greenwood, J. P., and R. E. Blake (2006), Evidence for an acidic ocean on Mars from phosphorus geochemistry of Martian soils and rocks, Geology, $34,953-956$

Gupta, S. C., T. J. Ahrens, and W. Yang (2001), Shock-induced vaporization of anhydrite and global cooling from the K/T impact, Earth Planet. Sci. Lett., 188, 399-412.

Haberle, R. M. (1998), Early Mars climate models, J. Geophys. Res., 103 $28,467-28,479$

Hamer, M., R. C. Graham, C. Amrhein, and K. N. Bozhilov (2003), Dissolution of ripidilite $(\mathrm{Mg}, \mathrm{Fe}$-chlorite) in organic and inorganic acid solutions, Soil Sci. Soc. Am. J., 67, 654-661.

Hamilton, V. E., M. B. Wyatt, H. Y. McSween, and P. R. Christensen (2001), Analysis of terrestrial and Martian volcanic compositions using thermal emission spectroscopy: 2. Application to Martian surface spectra from the Mars Global Surveyor Thermal Emission Spectrometer, J. Geophys. Res., 106, 14,733-14,746.

Haskin, L. A., et al. (2005), Water alteration of rocks and soils on Mars at the Spirit rover site in Gusev crater, Nature, 436, 66-69.

Helgeson, H. C. (1968), Evaluation of irreversible reactions in geochemical processes involving minerals and aqueous solutions: I. Thermodynamic relations, Geochim. Cosmochim. Acta, 32, 569-592.

Helgeson, H. C., J. Delany, and D. K. Bird (1978), Summary and critique of the thermodynamic properties of rock-forming minerals, Am. J. Sci., $278 A, 1-229$
Hoefen, T. M., R. N. Clark, J. L. Bandfield, M. D. Smith, J. C. Pearl, and P. R. Christensen (2003), Discovery of olivine in the Nili Fossae region of Mars, Science, 302, 627-630.

Holland, H. D. (1984), The Chemical Evolution of the Atmosphere and Oceans, 598 pp., Princeton Univ. Press, Princeton, N. J.

Holland, T. J. B., and R. Powell (1998), An internally consistent thermodynamic data set for phases of petrologic interest, J. Metamorph. Geol., $16,309-343$

Huertas, F. J., L. Chou, and R. Wollast (1999), Mechanism of kaolinite dissolution at room temperature and pressure, Part II: Kinetic study, Geochim. Cosmochim. Acta, 63, 3261-3275.

Huertas, F. J., E. Caballero, C. Jiménez de Cisneros, F. Huertas, and J. Linares (2001), Kinetics of montmorillonite dissolution in granitic solutions, Appl. Geochem., 16, 397-407.

Hurowitz, J. A., S. M. McLennan, D. H. Lindsley, and M. A. A. Schoonen (2005), Experimental epithermal alteration of synthetic Los Angeles meteorite: Implications for the origin of Martian soils and identification of hydrothermal sites on Mars, J. Geophys. Res., 110, E07002, doi:10.1029/2004JE002391.

Hurowitz, J. A., et al. (2006), In situ and experimental evidence for acidic weathering of rocks and soils on Mars, J. Geophys. Res., 111, E02S19, doi:10.1029/2005JE002515.

Icenhower, J. P., and P. M. Dove (2000), The dissolution kinetics of amorphous silica into sodium chloride solutions: Effects of temperature and ionic strength, Geochim. Cosmochim. Acta, 64, 4193-4203.

Ivanov, B. A., D. D. Badjukov, O. I. Yakovlev, M. V. Gerasimov, Y. P. Dikov, K. O. Pope, and A. C. Ocampo (1996), Degassing of sedimentary rocks due to Chicxulub impact: Hydrocode and physical simulations, in The Cretaceous-Tertiary Event and Other Catastrophes in Earth History, edited by G. Ryder, D. Fastovsky, and S. Gartner, Spec. Pap. Geol. Soc. Am., 307, 125-139.

Jakosky, B. M., and C. B. Farmer (1982), The seasonal and global behavior of water vapor in the Mars atmosphere: Complete global results of the Viking atmospheric water vapor detector experiment, J. Geophys. Res., 87, 2999-3019.

Klingelhöfer, G., et al. (2004), Jarosite and hematite at Meridiani Planum from opportunity's Mössbauer spectrometer, Science, 306, 1740-1745.

Knauth, L. P., D. M. Burt, and K. H. Wohletz (2005), Impact origin of sediments at the Opportunity landing site on Mars, Nature, 438, $1123-$ 1128 .

Kodama, H., and M. Schnitzer (1973), Dissolution of chlorite minerals by fulvic acid, Can. J. Soil Sci., 53, 240-243.

Kohyama, N., and T. Sudo (1975), Hisingerite occurring as a weathering product of iron-rich saponite, Clays Clay Miner., 23(3), 215-218.

Kraft, M., J. R. Michalski, and T. G. Sharp (2003), Effects of pure silica coatings on thermal emission spectra of basaltic rocks: Considerations for Martian surface mineralogy, Geophys. Res. Lett., 30(24), 2288, doi:10.1029/2003GL018848.

Kump, L., S. L. Brantley, and M. A. Arthur (2000), Chemical weathering, atmospheric $\mathrm{CO}_{2}$ and climate, Earth Planet. Sci. Rev., 28, 611-667.

Langmuir, D. (1997), Aqueous Environmental Geochemistry, 600 pp., Prentice-Hall, Upper Saddle River, N. J.

Lasaga, A. C. (1981), Transition state theory, in Kinetics of Geochemical Processes, Rev. Mineral., vol. 8, edited by A. C. Lasaga and R. J. Kirkpatrick, pp. 135-169, Mineral. Soc. of Am., Washington, D. C.

Lowson, R. T., M.-C. J. Comarmond, G. Rajaratnam, and P. L. Brown (2005), The kinetics of the dissolution of chlorite as a function of $\mathrm{pH}$ and at $25^{\circ} \mathrm{C}$, Geochim. Cosmochim. Acta, 69, 1687-1699.

Lyons, J. R., and T. J. Ahrens (1996), Chicxulub impact-induced vaporization: $\mathrm{S}$ and $\mathrm{C}$ species and their affect on global climate, Lunar Planet. Sci., XXVII, 787-788.

Marion, G. (2002), A molal-based model for strong acid chemistry at low temperatures (<200 to 298 K), Geochim. Cosmochim. Acta, 66, 24992516.

Marion, G. M., D. C. Catling, and J. S. Kargel (2003), Modeling aqueous ferrous chemistry at low temperatures with application to Mars, Geochim. Cosmochim. Acta, 67, 4251-4266.

McAdam, A. C., M. Y. Zolotov, M. V. Mironenko, and T. G. Sharp (2007a), Preferential low-pH dissolution of pyroxene in plagioclase-pyroxene mixtures and implications for Martian low-albedo regions, Lunar Planet. Sci. [CD-ROM], XXXVIII, Abstract 1871

McAdam, A. C., M. Y. Zolotov, M. V. Mironenko, and T. G. Sharp (2007b), Acid weathering of basaltic lithologies: Equilibrium modeling and applications to Mars, Lunar Planet. Sci. [CD-ROM], XXXVIII, Abstract 2198.

McCollom, T. M., and B. M. Hynek (2005), A volcanic environment for bedrock diagenesis at Meridiani Planum on Mars, Nature, 438, 11291131.

McKay, G. A., T. Mikouchi, C. Schwandt, and G. Lofgren (1998), Fracture fillings in ALH84001 feldspatic glass: Carbonates and silica, Lunar Planet. Sci. [CD-ROM], XXIX, Abstract 1944 
McLennan, S. M. (2003), Sedimentary silica on Mars, Geology, 31(4), $315-318$

McLennan, S. M., et al. (2005), Prevalence and diagenesis of the Burns formation, Meridiani Planum, Mars, Earth Planet. Sci. Lett., 240, $95-$ 121.

McSween, H. Y., and E. Jarosewich (1983), Petrogenesis of the Elephant Moraine A79001 meteorite: Multiple magma pulses on the shergottite parent body, Geochim. Cosmochim. Acta, 47, 1501-1513.

McSween, H. Y., T. L. Grove, and M. B. Wyatt (2003), Constraints on the composition and petrogenesis of the Martian crust, J. Geophys. Res. 108(E12), 5135, doi:10.1029/2003JE002175.

McSween, H. Y., et al. (2004), Basaltic rocks analyzed by the Spirit Rover in Gusev crater, Science, 305, 842-845.

McSween, H. Y., et al. (2006), Characterization and petrologic interpretation of olivine-rich basalts at Gusev crater, Mars, J. Geophys. Res., 111, E02S10, doi:10.1029/2005JE002477.

Meunier, A. (2005), Clays, 472 pp., Springer, Berlin.

Michalski, J. R., M. D. Kraft, T. G. Sharp, L. B. Williams, and P. R. Christensen (2005), Mineralogical constraints on the high-silica Martian surface component observed by TES, Icarus, 174, 161-177.

Michalski, J. R., M. D. Kraft, T. G. Sharp, L. B. Williams, and P. R Christensen (2006a), Emission spectroscopy of clay minerals and evidence for poorly crystalline aluminosilicates on Mars from Thermal Emission Spectrometer data, J. Geophys. Res., 111, E03004, doi:10.1029/2005JE002438.

Michalski, J. R., M. D. Kraft, T. G. Sharp, and P. R. Christensen (2006b), Effects of chemical weathering on infrared spectra of Columbia River Basalt and spectral interpretations of Martian alteration, Earth Planet. Sci. Lett., 248, 822-829.

Millero, F. J., S. Sotolongo, and M. Izaguirre (1987), The oxidation kinetics of Fe(II) in seawater, Geochim. Cosmochim. Acta, 51, 793-801.

Ming, D. W., et al. (2006), Geochemical and mineralogical indicators for aqueous processes in the Columbia Hills of Gusev crater, Mars, J. Geophys. Res., 111, E02S12, doi:10.1029/2005JE002560.

Mironenko, M. V., N. N. Akinfiev, and T. Y. Melikhova (2000), GEOCHEQ - The complex for thermodynamic modeling of geochemical systems, Herald DGGGMS RAS, 5(15), 96-97.

Morris, R. V., and H. V. Lauer Jr. (1980), The case against UV photostimulated oxidation of magnetite, Geophys. Res. Lett., 7, 605-608.

Morris, R. V., et al. (2000), Mineralogy, composition, and alteration of Mars Pathfinder rocks and soils: Evidence from multispectral, elemental, and magnetic data on terrestrial analogue, SNC meteorite, and Pathfinder samples, J. Geophys. Res., 105, 1757-1817.

Morris, R. V., et al. (2006), Mössbauer mineralogy of rock, soil, and dust at Gusev crater, Mars: Spirit's journey through weakly altered olivine basalt on the plains and pervasively altered basalt in the Columbia Hills, J. Geophys. Res., 111, E02S13, doi:10.1029/2005JE002584.

Murchie, S. J., L. Kirkland, S. Erard, J. Mustard, and M. Robinson (2000), Near-infrared spectral variations of Martian surface materials from ISM imaging spectrometer data, Icarus, 147, 444-471.

Murphy, W. M., and H. C. Helgeson (1989), Thermodynamic and kinetic constraints on reaction rates among minerals and aqueous solutions, $\mathrm{Am}$. J. Sci., 289, 17-101.

Mustard, J. F., and C. D. Cooper (2005), Joint analysis of ISM and TES spectra: The utility of multiple wavelength regimes for Martian surface studies, J. Geophys. Res., 110, E05012, doi:10.1029/2004JE002355.

Mustard, J. F., F. Poulet, A. Gendrin, J.-P. Bibring, Y. Langevin, B. Gondet, N. Mangold, G. Bellucci, and F. Altieri (2005), Olivine and pyroxene diversity in the crust of Mars, Science, 307, 1594-1597.

Nagy, K. L., A. E. Blum, and A. C. Lasaga (1991), Dissolution and precipitation kinetics of kaolinite at $80^{\circ} \mathrm{C}$ and $\mathrm{pH}$ 3: The dependence on solution saturation state, Am. J. Sci., 291, 649-686.

Pierazzo, E., D. A. Kring, and H. J. Melosh (1998), Hydrocode simulation of the Chicxulub impact event and the production of climatically active gases, J. Geophys. Res., 103, 28,607-28,625.

Plummer, L. N., and E. Busenberg (1982), The solubilities of calcite, aragonite, and vaterite in $\mathrm{CO}_{2}-\mathrm{H}_{2} \mathrm{O}$ solutions between 0 and $90^{\circ} \mathrm{C}$, and an evaluation of the aqueous model for the system calcium carbonate-carbon dioxide-water, Geochim. Cosmochim. Acta, 46, 1011-1040.

Pokrovsky, O. S., and J. Schott (2000), Kinetics and mechanism of forsterite dissolution at $25^{\circ} \mathrm{C}$ and $\mathrm{pH}$ from 1 to 12 , Geochim. Cosmochim. Acta, 64, 3313-3325.

Pollack, J. B., D. S. Colburn, F. M. Flasar, R. Kahn, C. E. Carlston, and D. G. Pidek (1979), Properties and effects of dust particles suspended in the Martian atmosphere, J. Geophys. Res., 84, 2929-2945.

Pope, K. O., K. H. Baines, A. C. Ocampo, and B. A. Ivanov (1997), Energy, volatile production, and climatic effects of the Chicxulub Cretaceous/Tertiary impact, J. Geophys. Res., 102, 21,645-21,664.

Poulet, F., et al. (2005), Phyllosilicates on Mars and implications for early Martian climate, Nature, 438, 623-627.
Prinn, R. G., and B. Fegley Jr. (1987), Bolide impacts, acid rain, and biospheric traumas at the Cretaceous-Tertiary boundary, Earth Planet. Sci. Lett., 83, 1-15.

Rampe, E. B., M. D. Kraft, T. G. Sharp, and J. R. Michalski (2006), Thermal infrared spectroscopy and modeled mineralogy of fine-grained mineral mixtures: Implications for Martian surface mineralogy, Eos Trans. $A G U, 87(52)$, Fall Meet. Suppl., Abstract P21A-06.

Richardson, M. I., and M. A. Mischna (2005), Long-term evolution of transient liquid water on Mars, J. Geophys. Res., 110, E03003, doi:10.1029/2004JE002367.

Rieder, R., et al. (2004), Chemistry of rocks and soils at Meridiani Planum from the alpha particle X-ray spectrometer, Science, 306, 1746-1749.

Rimstidt, J. D., and H. L. Barnes (1980), The kinetics of silica-water reactions, Geochim. Cosmochim. Acta, 44, 1683-1699.

Robie, R. A., and B. S. Hemingway (1995), Thermodynamic properties of minerals and related substances at $298.15 \mathrm{~K}$ and 1 bar $\left(10^{5}\right.$ pascals $)$ pressure and higher temperatures, U.S. Geol. Surv., 2131.

Rogers, A. D., J. L. Bandfield, and P. R. Christensen (2007), Global spectral classification of Martian low-albedo regions with Mars Global Surveyor Thermal Emission Spectrometer (MGS-TES) data, J. Geophys. Res., 112, E02004, doi:10.1029/2006JE002726.

Ruff, S. W., P. R. Christensen, D. L. Blaney, W. H. Farrand, J. R. Johnson, J. R. Michalski, J. E. Moersch, S. P. Wright, and S. W. Squyres (2006), The rocks of Gusev crater as viewed by the Mini-TES instrument, J Geophys. Res., 111, E12S18, doi:10.1029/2006JE002747.

Schiffman, P., R. Zierenberg, N. Marks, J. L. Bishop, and M. D. Dyar (2006), Acid-fog deposition at Kilauea volcano: A possible mechanism for the formation of siliceous-sulfate rock coatings on Mars, Geology, 34, $921-924$

Segura, T. L., O. B. Toon, A. Colaprete, and K. Zahnle (2002), Environmental effects of large impacts on Mars, Science, 298, 1977-1980.

Settle, M. (1979), Formation and deposition of volcanic sulfate aerosols on Mars, J. Geophys. Res., 84, 8343-8354.

Shock, E. L., H. C. Helgeson, and D. A. Sverjensky (1989), Calculation of the thermodynamic and transport properties of aqueous species at high pressures and temperatures: Standard partial and molar properties of inorganic neutral species, Geochim. Cosmochim. Acta, 53, 2157-2183.

Shock, E. L., D. C. Sassani, M. Willis, and D. A. Sverjensky (1997), Inorganic species in geologic fluids: Correlations among standard molal thermodynamic properties of aqueous ions and hydroxide complexes, Geochim. Cosmochim. Acta, 61, 907-950.

Sidhu, P. S., R. J. Gilkes, R. M. Coenell, A. M. Posner, and J. P. Qurik (1981), Dissolution of iron oxides and oxyhydroxides in hydrolic and perhydrolic acids, Clays Clay Miner., 29, 269-276.

Singer, P. C., and W. Stumm (1970), Acid mine drainage: The rate-determining step, Science, 167, 1121-1123

Soderblom, L. A. (1992), The composition and mineralogy of the Martian surface from spectroscopic observations: $0.3 \mathrm{~mm}$ to $50 \mathrm{~mm}$, in Mars, edited by H. H. Kieffer et al., pp. 557-593, Univ. of Ariz. Press, Tucson. Symonds, R. B., W. I. Rose, G. J. S. Bouth, and T. M. Gerlach (1994), Volcanic-gas studies: Methods, results, and applications, in Volatiles in Magmas, Rev. Mineral., vol. 30, edited by M. R. Carroll and J. R. Holloway, pp. 1-66, Mineral. Soc. of Am., Washington, D. C.

Tanaka, K. L., D. H. Scott, and R. Greeley (1992), Global stratigraphy, in Mars, edited by H. H. Kieffer et al., pp. 345-382, Univ. of Ariz. Press, Tucson.

Tosca, N. J., S. M. McLennan, D. H. Lindsley, and A. A. Schoonen (2004), Acid-sulfate weathering of synthetic Martian basalt: The acid fog model revisited, J. Geophys. Res., 109, E05003, doi:10.1029/2003JE002218.

Tosca, N. J., S. M. McLennan, B. C. Clark, J. P. Grotzinger, J. A. Hurowitz, A. H. Knoll, C. Schröder, and S. E. Squyres (2005), Geochemical modeling of evaporation processes on Mars: Insight from the sedimentary record at Meridiani Planum, Earth Planet. Sci. Lett., 240, 122-148.

Vieillard, P., S. Ramirez, A. Bouchet, A. Cassagnabere, A. Meunier, and E. Jacquot (2004), Alteration of the Callovo-Oxfordian clay from MeuseHaute Marne underground laboratory (France) by alkaline solution: II. Modeling of mineral reactions, Appl. Geochem., 19, 1699-1709.

Wang, A., et al. (2006a), Evidence of phyllosilicates in Wooly Path, an altered rock encountered at West Spur, Columbia Hills, by the Spirit Rover in Gusev crater, Mars, J. Geophys. Res., 111, E02S16, doi:10.1029/ 2005JE002516.

Wang, A., et al. (2006b), Sulfate deposition in subsurface regolith in Gusev crater, Mars, J. Geophys. Res., 111, E02S17, doi:10.1029/2005JE002513.

Warren, P. H. (1998), Petrologic evidence for low-temperature, possible flood evaporitic origin of carbonates in the ALH84001 meteorite, J. Geophys. Res., 103, 16,759-16,773

Westall, F., P. Gobbi, D. Gerneke, and G. Mazzotti (1998), Microstructures in the carbonate globules of Martian meteorite ALH84001: Preliminary results of a high resolution SEM study, Lunar Planet Sci. [CD-ROM], $X X I X$, Abstract 1362 
White, A. F. (2004), Natural weathering rates of silicate minerals, in Treatise on Geochemistry, vol. 5, Surface and Ground Water, Weathering, and Soils, edited by J. I. Drever, pp. 133-168, Pergamon, Oxford, U. K.

White, A. F., and S. L. Brantley (Eds.) (1995), Chemical Weathering Rates of Silicate Minerals, Rev. Mineral., vol. 31, Mineral. Soc. of Am., Washington, D. C.

White, A. F., and S. L. Brantley (2003), The effect of time on the weathering of silicate minerals: Why do weathering rates differ in the laboratory and field?, Chem. Geol., 202, 479-506.

White, A. F., M. L. Peterson, and M. F. Hochella Jr. (1994), Electrochemistry and dissolution kinetics of magnetite and ilmenite, Geochim. Cosmochim. Acta, 58, 1859-1875.

Wilson, J., D. Savage, J. Cuadros, M. Shibata, and K. V. Ragnarsdottir (2006), The effect of iron on montmorillonite stability: I. Background and thermodynamic considerations, Geochim. Cosmochim. Acta, 70, $306-322$

Wogelius, R. A., and J. V. Walther (1992), Olivine dissolution kinetics at near-surface conditions, Chem. Geol., 97, 101-112.

Wolery, T. J., and C. F. Jove-Colon (2004), Qualification of thermodynamic data for geochemical modeling of mineral-water interactions in dilute systems, Rep. ANL-WIS-GS-000003 REV 00, U.S. Dep. of Energy, Washington, D. C.

Wolfe, E. W., W. S. Wise, and G. B. Dalrymple (1997), The geology and petrology of Mauna Kea volcano, Hawaii: A study of postshield volcanism, U.S. Geol. Surv. Prof. Pap., 1557, 129 pp.

Wyatt, M. B., and H. Y. McSween (2002), Spectral evidence for weathered basalt as an alternative to andesite in the northern lowlands of Mars, Nature, 417, 263-266.
Yen, A. S., S. S. Kim, M. H. Hecht, M. S. Frant, and B. Murray (2000), Evidence that the reactivity of the Martian soil is due to superoxide ions, Science, 289, 1909-1912.

Yung, Y. L., and W. D. DeMore (1999), Photochemistry of Planetary Atmospheres, 456 pp., Oxford Univ. Press, New York.

Zolotov, M. Y. (1989), Water-bearing minerals in the Martian soil (thermodynamic prediction of stability), Lunar Planet. Sci., XX, 12571258.

Zolotov, M. Y. (2003), Martian volcanic gases: Are they terrestrial-like?, Lunar Planet. Sci. [CD-ROM], XXXIV, Abstract 1795.

Zolotov, M. Y., and E. L. Shock (2005), Formation of jarositebearing deposits through aqueous oxidation of pyrite at Meridiani Planum, Mars, Geophys. Res. Lett., 32, L21203, doi:10.1029/ 2005GL024253.

Zolotov, M. Y., E. L. Shock, P. Niles, and L. Leshin (2004), Martian subsurface waters: Alkaline and reduced throughout history, in Second Conference on Early Mars: Geologic, Hydrologic, and Climatic Evolution and the Implications for Life [CD-ROM], Abstract 8036, Lunar Planet. Inst., Houston, Tex.

M. V. Mironenko, Vernadsky Institute of Geochemistry and Analytical Chemistry, Russian Academy of Sciences, 19 Kosygin Street, Moscow 119991, Russia.

M. Y. Zolotov, School of Earth and Space Exploration, Arizona State University, Tempe, AZ 85287-1404, USA. (zolotov@asu.edu) 